Florida International University FIU Digital Commons

\title{
Distribution Fits for Various Parameters in the Hurricane Model
}

Victoria Oxenyuk

Florida International University, vikusek@gmail.com

DOI: $10.25148 /$ etd.FI14040863

Follow this and additional works at: https://digitalcommons.fiu.edu/etd

Part of the Applied Statistics Commons, Atmospheric Sciences Commons, and the Other Statistics and Probability Commons

\section{Recommended Citation}

Oxenyuk, Victoria, "Distribution Fits for Various Parameters in the Hurricane Model" (2014). FIU Electronic Theses and Dissertations. 1366.

https://digitalcommons.fiu.edu/etd/1366

This work is brought to you for free and open access by the University Graduate School at FIU Digital Commons. It has been accepted for inclusion in FIU Electronic Theses and Dissertations by an authorized administrator of FIU Digital Commons. For more information, please contact dcc@fiu.edu. 


\section{FLORIDA INTERNATIONAL UNIVERSITY}

Miami, Florida

\section{DISTRIBUTION FITS FOR VARIOUS PARAMETERS \\ IN THE HURRICANE MODEL}

A thesis submitted in partial fulfillment of

the requirements for the degree of

MASTER OF SCIENCE

in

STATISTICS

by

Victoria Oxenyuk 
To: Dean Kenneth G. Furton

College of Arts and Sciences

This thesis, written by Victoria Oxenyuk, and entitled Distribution Fits for Various Parameters in the Hurricane Model, having been approved in respect to style and intellectual content, is referred to you for judgment.

We have read this thesis and recommend that it be approved.

Shahid S. Hamid

B.M. Golam Kibria, Co-Major Professor

Sneh Gulati, Co-Major Professor

Date of Defense: March 20, 2014

The thesis of Victoria Oxenyuk is approved.

Dean Kenneth G. Furton
College of Arts and Sciences

Dean Lakshmi N. Reddi University Graduate School

Florida International University, 2014 
ABSTRACT OF THE THESIS

DISTRIBUTION FITS FOR VARIOUS PARAMETERS

IN THE HURRICANE MODEL

\author{
by \\ Victoria Oxenyuk \\ Florida International University, 2014 \\ Miami, Florida \\ Professor Sneh Gulati, Co-Major Professor \\ Professor B.M. Golam Kibria, Co-Major Professor
}

The FPHLM is the only open public hurricane loss evaluation model available for assessment of hazard to insured residential property from hurricanes in Florida. The model consists of three independent components: the atmospheric science component, the vulnerability component and the actuarial component. The atmospheric component simulates thousands of storms, their wind speeds and their decay once on land on the basis of historical hurricane statistics defining wind risk for all residential zip codes in Florida.

The focus of the thesis was to analyze atmospheric science component of the Florida Public Hurricane Loss Model, replicate statistical procedures used to model various parameters of atmospheric science component and to validate the model. I establish the distribution for modeling annual hurricane occurrence, choose the best fitting distribution for the radius of maximum winds and compute the expression for the pressure profile parameter Holland B. 


\section{TABLE OF CONTENTS}

CHAPTER

PAGE

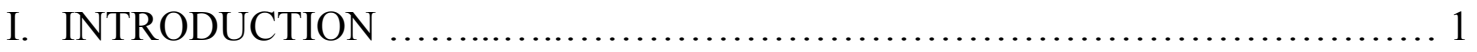

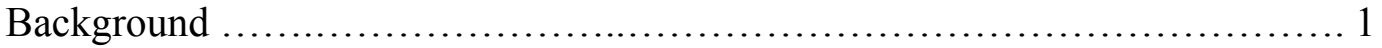

Problem Description ...................................................... 2

Theoretical Perspective ........................................................ 3

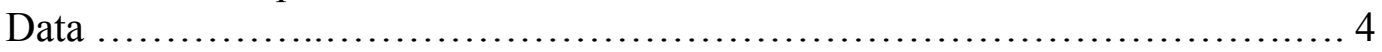

Project Organization .................................................... 5

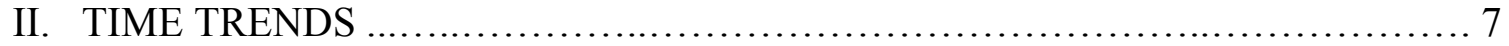

III. ANNUAL HURRICANE OCCURRENCE ….............................. 10

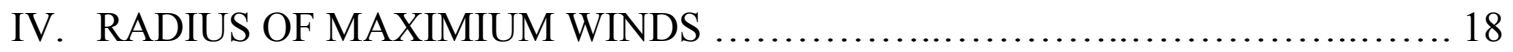

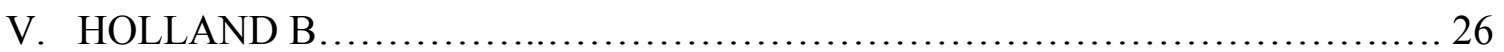

VI. FINAL RESULTS AND CONCLUSIONS …................................. 32

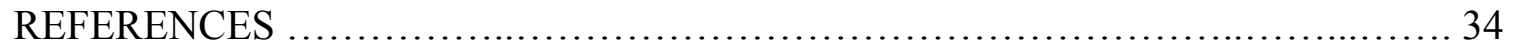

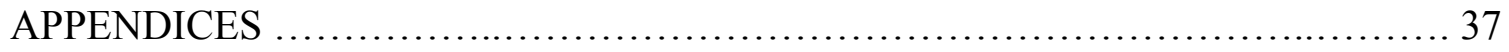




\section{INTRODUCTION}

\section{Background}

Hurricanes are one of the greatest natural hazards; although relatively rare in occurrence they can cause colossal economic losses. In 1992, "when Hurricane Andrew struck Florida it caused over $\$ 30$ billion in direct economic losses" (Lokupitiya et al., 2005). Hurricane modeling has become a widely used tool for assessing risks associated with windstorm catastrophes. Since the groundbreaking studies of Russell $(1968,1971)$ and Tryggvason et al. (1976) the modeling methods have improved significantly as a consequence of increased computing capabilities, new advanced physical and statistical models and vast growth in quantity and quality of available data. Several private models for simulating hurricane loss have been developed in the recent years for use in the State of Florida but such models are typically commercial and are not available to research community and public. The Florida Public Hurricane Loss Model (FPHLM) is a notable exception.

The FPHLM is an open public hurricane loss evaluation model which was developed as a joint effort of specialists in fields of meteorology, engineering, computer science, actuarial science, finance and statistics from Florida International University, NOAA Hurricane Research Division, University of Miami, Florida State University, Florida Institute of Technology and University of Florida. The model was created "for a purpose of probabilistic assessment of risk to insured residential property associated with wind damage from hurricanes" (Hamid et al., 2010). The FPHLM consists of three main components (Figure 1): first - the atmospheric science component which models the 
track and intensity of hurricanes in Florida threat area; second - the engineering component which models vulnerability of insured property; and third - the actuarial science component which models the insured loss. The atmospheric science component simulates thousands of storms, their wind speeds and their decay once on land on the basis of historical hurricane statistics defining wind risk for all residential zip codes in Florida. The wind risk information is then passed on to the engineering and actuarial science components to assess damage and annual loss. Each component is developed independently and delivered as a one-way input to the next component in line until the end result is achieved.

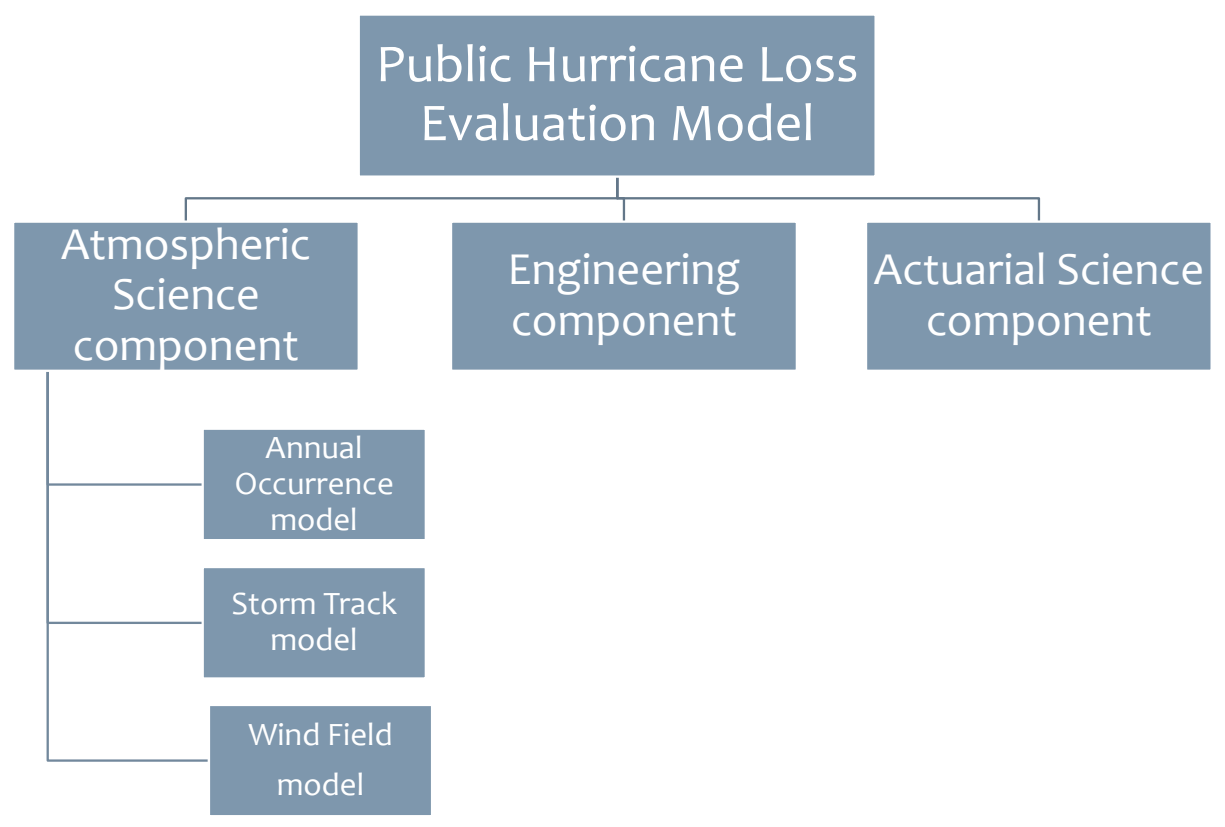

Figure 1. Structure of FPHLM

\section{Problem Description}

The aim of my thesis is to analyze atmospheric science component of FPHLM, repeat statistical procedures that were used to model parameters of meteorological component and to validate the model. 


\section{Theoretical Perspective}

The atmospheric component of FPHLM includes annual occurrence model, which simulates the number of storms in a year, the storm track model, demonstrating the trajectory and intensity of hurricanes, and the wind field model.

Modeling annual hurricane occurrence (AHO) is the first step of atmospheric science component. Since the available historical data of documented hurricanes are limited, simulation that replicates fundamental characteristics of existing data has to be run to supplement the number of hurricanes. Statistical distribution of the number of hurricanes occurring per year is essential for such a simulation. "According to domain knowledge in meteorology, the best statistical distribution of the number of hurricanes occurring per year is either the Poisson distribution or the Negative Binomial distribution" (Chen et al., 2003).

One of the goals of my thesis is to determine which of the two distributions is the best for modeling AHO: Poisson distribution that assumes homogenous hurricane frequencies (the mean number of hurricanes in any two years is the same) or Negative binomial distribution that assumes non-homogenous annual occurrence rate.

Wind field model is another component within a hurricane risk model, which is dedicated to simulating hurricanes, their wind speeds and their decay once on land on the basis of historical data. The wind field model is later used for engineering simulation of the damage to insured property and actuarial calculation of the resulting loss.

Two fundamental components of the wind field model are radius of maximum winds $\left(R_{\max }\right)$ and central pressure at landfall. These two variables are most relevant for estimating loss since the greater the area of strike the greater the damage and the lower 
the central pressure the more intense the hurricane. The radius of maximum winds has a substantial impact on the area affected by the hurricane and modeling of $R_{\max }$ influences the likelihood of the location experiencing strong winds in cases of near misses. Modeling the distribution of $R_{\max }$ is therefore critical for estimating the possible losses for insurance pricing purposes.

The FPHLM finds the Gamma distribution to be the best fit for the $R_{\max }$. In the present thesis I will determine how well Gamma distribution fits the $R_{\max }$ data and try to find if there are distributions that fit the data better than the Gamma distribution.

Holland $B$ is an additional parameter defining the pressure field and maximum wind speeds in a hurricane. It was introduced by Holland (1980) and has been used in many hurricane threat studies since (Powell et al., 2005, Emanuel et al., 2006, Lee and Rosowsky, 2007, Hall and Jewson, 2008, and Vickery et al., 2009).

As a pressure profile parameter Holland $B$ allows for the distinction in the maximum wind speeds observed in hurricanes for a given $\Delta p$ (difference between central minimum sea level pressure and an outer peripheral pressure) all else being equal. The omission of $B$ results in maximum wind speeds proportional to $\sqrt{\Delta p}$, whereas with $B$ the maximum wind speed in the simulated hurricane is proportional to $\sqrt{B \Delta p}$.

The FPHLM shows that Holland $B$ parameter is inversely correlated with both the size and latitude of the hurricane. Finding an exact statistical relationship between $B$ and radius of maximum winds and latitude is another goal of the present research.

\section{Data}

The analysis of annual hurricane occurrence and radius of maximum winds will use data obtained from historical record for the Atlantic tropical cyclone basin (known as 
"HURDAT") for the period from 1901 until 2010. Earlier data are available but not used because of the lack of population centers and uncertainties about meteorological measurements before the start of 20th century.

A model for the Holland B pressure profile parameter will be developed on the basis of a subset of the data published by Willoughby and Rahn (2004) and obtained by NOAA and U.S. Air Force Reserve aircraft between 1977 and 2000.

To find the best fitting distribution the preliminary analysis of the data will be done through the use of EasyFit software which allows us to easily fit a large number of distributions to the data. Estimated parameters of the best fitting distributions will then be found using maximum likelihood estimator (MLE) method. In order to determine how well the selected distributions fit the data they will be tested for goodness-of-fit using Kolmogorov-Smirnov, Anderson-Darling and Chi-Square tests. Along with the goodness of fit tests the probability density function graphs, Q-Q and P-P plots will be used to visually assess the goodness of fit and empirically compare several fitted models. In order to determine the model for estimating Holland $\mathrm{B}$, multiple regression analysis will be performed using the Proc REG procedure in SAS.

\section{Project Organization}

The purpose of my research is to examine the first part of the Florida Public Hurricane Loss Model - the atmospheric component - and check distributions of several parameters of the model. The thesis consists of six chapters and four appendices.

In the second chapter I look at the available data from the historical prospective and check for increasing trends in hurricane intensity, size or number of hurricanes 
striking Florida. The third chapter establishes the distribution for modeling annual hurricane occurrence. In the fourth chapter the best fitting distribution for the radius of maximum winds is identified, and finally in the fifth chapter the expression for the pressure profile parameter Holland $B$ is computed.

The last chapter presents the final results and conclusions. The appendices contain databases for radius of maximum winds and Holland B as well as SAS codes and outputs. 


\section{TIME TRENDS}

One of the important questions asked by scientists when discussing the FPHLM is "whether the distribution of hurricane loss should reflect climate change (i.e., an increasing trend in hurricane intensity)" (Katz, 2010). Indeed climate change has been a growing topic of discussion so it would only be reasonable to suspect increasing trend in hurricane intensity, size or number of hurricanes striking Florida. The parameters of the FPHLM are assessed from the historical record under the assumption of stationarity and the validation of this assumption will be an important aspect of my research.

The debate about whether warming tropical sea surface temperatures are producing more intense and long-lived cyclones has been going on for over a decade. Although Emanuel (2005) and Webster et al. (2005) have found that intensity and number of hurricanes show an increasing trend, studies by Klotzbach (2006) and Shapiro and Goldenberg (1998) conclude that most of this increase is most likely a result of improved observational technology.

First I will look at the hurricane occurrence and see if the number of hurricanes has been higher in the recent years.

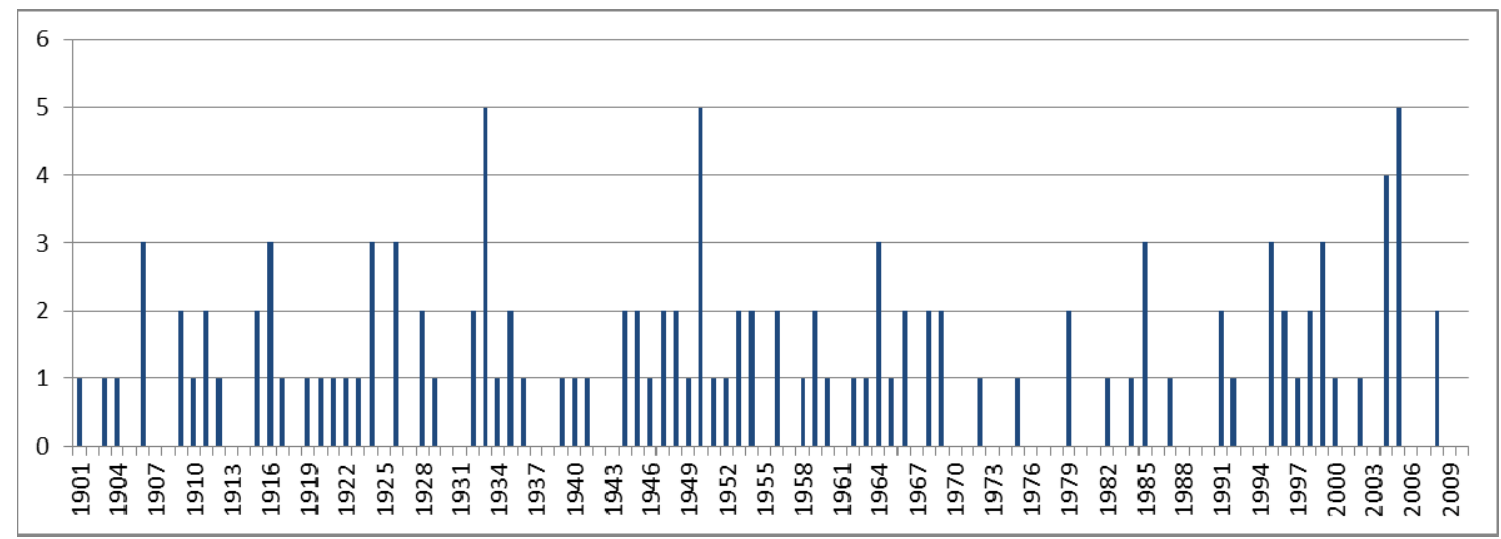

Figure 2. Number of hurricanes 
The time series of annual hurricane counts (Figure 2) does not suggest a growing trend. There are also no other visible patterns. The number of hurricanes occurring in a year does not appear to be increasing.

If frequency of damaging hurricanes is rising then it should be seen on the plot of radius of maximum winds in time or the plot of central pressure in time.

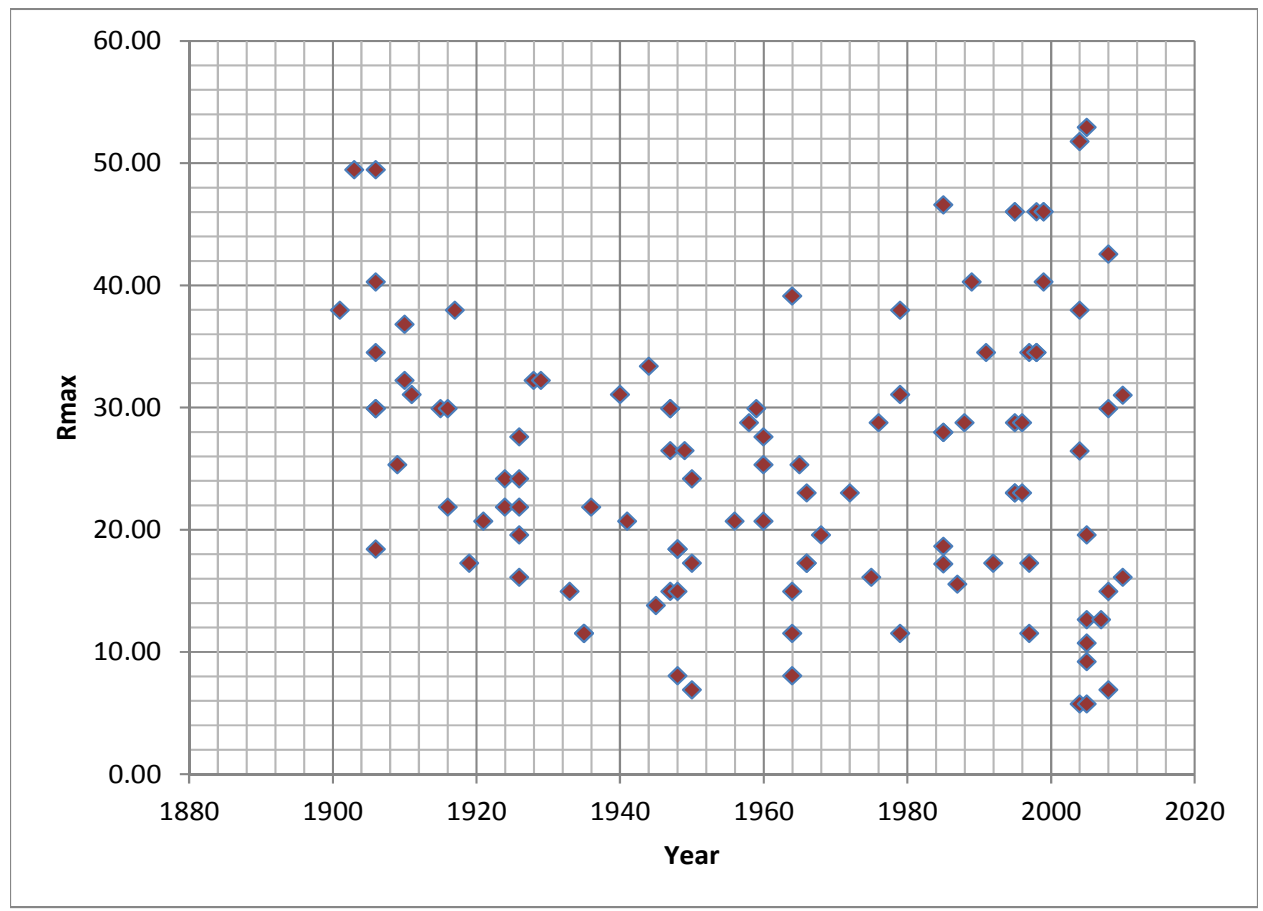

Figure 3. Plot of Radius of Maximum Winds vs. Time

The plot of radius of maximum winds (Figure 3) reveals higher values of Rmax in 1910s as well as 1990s and 2000s but no clear increasing trend can be detected.

The plot of central pressure in time (Figure 4) does not show any increase in hurricane strength. There are few higher values in 1980s but those indicate hurricanes of lower intensity. The strongest hurricanes with lowest central pressures are in 1920s, 1960s and 1990s-2000s. Thus I conclude that there is no evidence of increasing trend in hurricane intensity or size. 


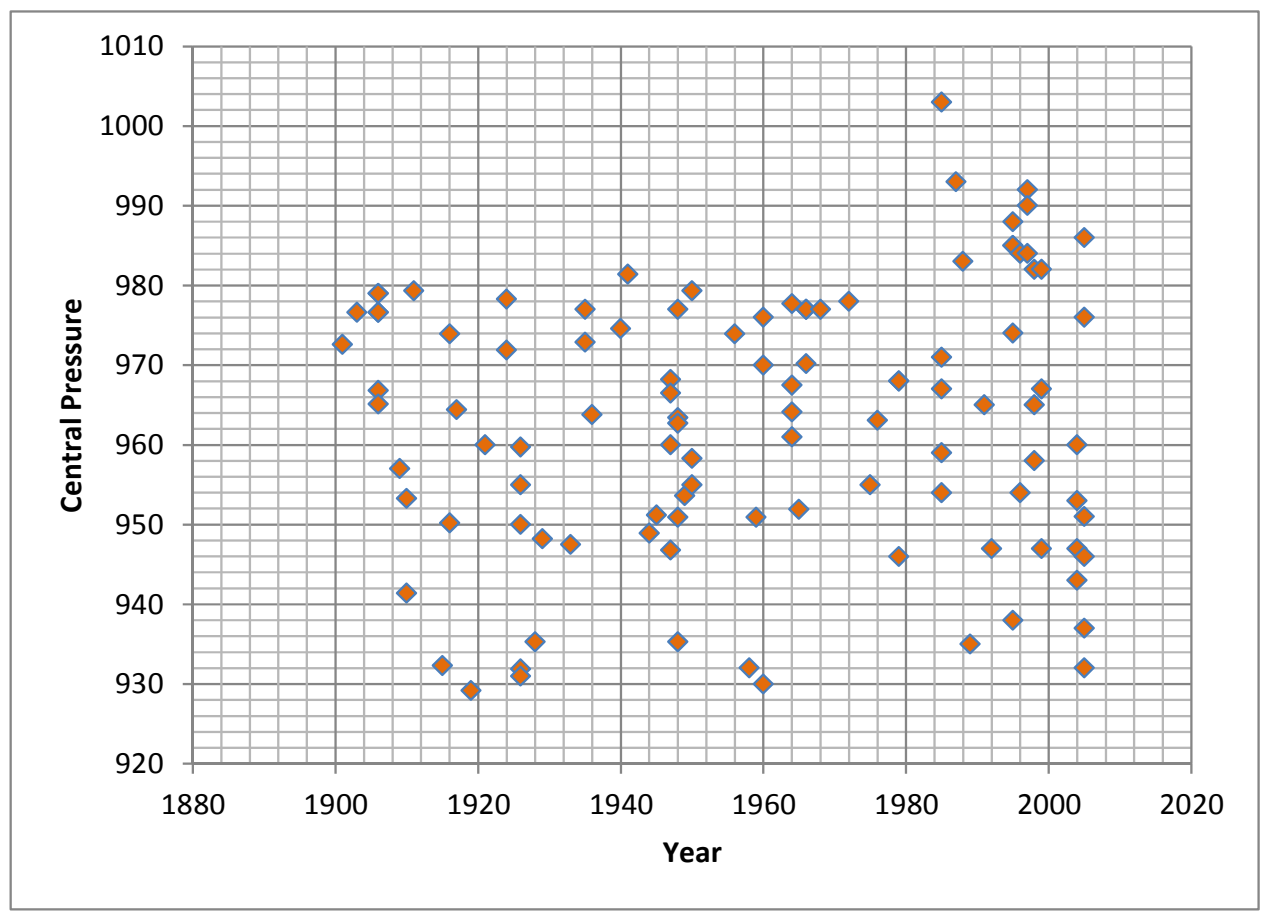

Figure 4. Plot of Central Pressure vs. Time

My findings do not support the argument that global tropical cyclone intensity, frequency and longevity have undergone increases in recent years. I conclude that no significant increasing trend is evident. 


\section{ANNUAL HURRICANE OCCURRENCE}

The first step in study of hurricanes and their impacts is to determine the frequency with which they occur. Annual Hurricane Occurrence (AHO) rate estimates "the frequency of hurricanes occurring in a series of years based on an associated hurricane occurrence probability distribution, which is obtained through statistical analysis and calculation on the basis of historical hurricane records" (Chen et al., 2003). Substantial research in the area of modeling occurrence of hurricanes has been done in recent years by Chen et al. (2003 and 2004), Gray et al. (1992), Elsner and Schmertmann (1993), Elsner and Jagger (2004). The basic principle of these papers was to generate the statistical models from the available historical data in order to estimate AHO. Using obtained probability distributions the number of hurricanes per year in the future is produced for a desired number of years.

Rare events in meteorology are classically described by the Poisson and the Negative Binomial distributions. The rate of occurrence of a stochastic process is typically described by the use of the Poisson distribution. However, Poisson distribution assumes the mean number of storms in any two non-overlapping time intervals of the same length to be equal. To allow those means to be unequal will lead to the annual occurrence modeled by a Negative Binomial distribution. General guiding principles as to the adequacy of the two distributions have been discussed (Thom, 1966) but one cannot accurately determine which model is appropriate until tests are conducted.

In this section I will determine whether either Poisson or Negative Binomial is adequate in describing the distribution of the annual hurricane occurrence. 
For the assessment of the AHO distribution to be conducted, a suitable dataset has to be obtained. Annual counts of tropical storms and hurricanes in the Atlantic Ocean are obtained from HURDAT database, which is maintained by the National Hurricane Center in Miami, Florida and the National Climatic Data Center in Asheville, North Carolina. The historical record for the Atlantic tropical cyclone basin contains six hourly record positions and intensities of tropical storm and hurricane for the period from 1851 to 2010 . Only data beginning the 1901 are going to be used in my research because of unreliability of $19^{\text {th }}$ century data. To focus on storms capable of affecting residential property in Florida, only storms in threat area (Figure 5) - within $1000 \mathrm{~km}$ of a location $(26.0 \mathrm{~N}, 82.0$ W) are being counted.

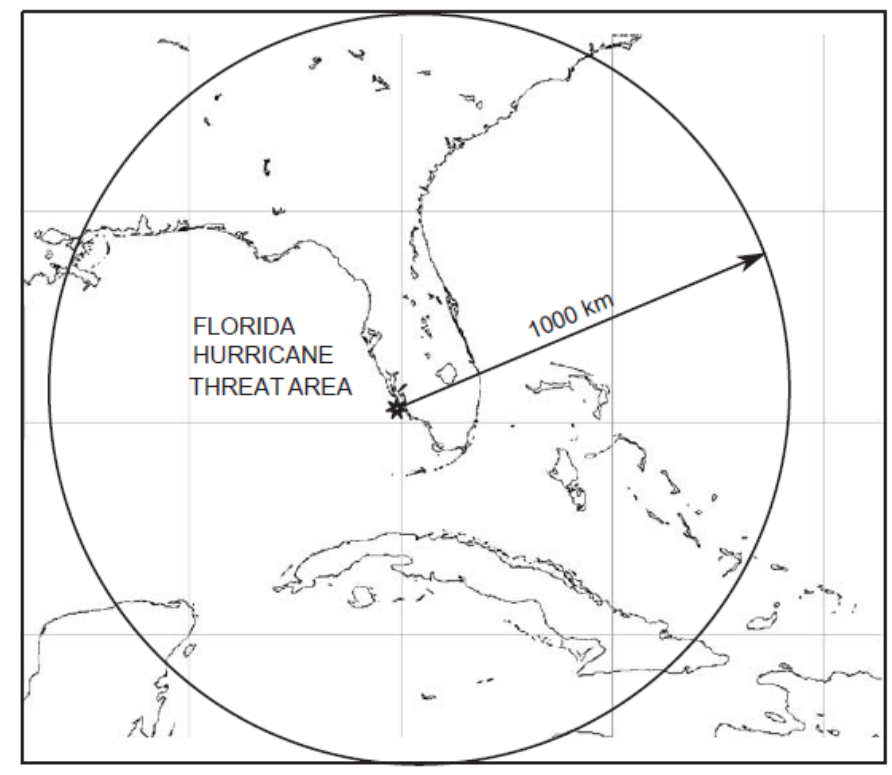

Figure 5. Florida Hurricane Threat Area

In order to obtain the number of hurricanes in each year from 1901 to $2010 \mathrm{I}$ looked at each hurricane and its six hourly positions recorded by HURDAT. If hurricane 
entered threat area at any time during its track it had been counted so that any hurricanes could only be counted once. The results are presented in Table 1.

Table 1. Annual Number of Hurricanes

\begin{tabular}{|c|c|c|c|c|c|c|c|c|c|c|c|}
\hline Year & $\begin{array}{c}\text { Total } \\
\text { hurricanes }\end{array}$ & Year & $\begin{array}{c}\text { Total } \\
\text { hurricanes }\end{array}$ & Year & $\begin{array}{c}\text { Total } \\
\text { hurricanes }\end{array}$ & Year & $\begin{array}{c}\text { Total } \\
\text { hurricanes }\end{array}$ & Year & $\begin{array}{c}\text { Total } \\
\text { hurricanes }\end{array}$ & Year & $\begin{array}{c}\text { Total } \\
\text { hurricanes }\end{array}$ \\
\hline 1901 & 1 & 1921 & 1 & 1941 & 1 & 1961 & 0 & 1981 & 0 & 2001 & 0 \\
\hline 1902 & 0 & 1922 & 1 & 1942 & 0 & 1962 & 1 & 1982 & 1 & 2002 & 1 \\
\hline 1903 & 1 & 1923 & 1 & 1943 & 0 & 1963 & 1 & 1983 & 0 & 2003 & 0 \\
\hline 1904 & 1 & 1924 & 3 & 1944 & 2 & 1964 & 3 & 1984 & 1 & 2004 & 4 \\
\hline 1905 & 0 & 1925 & 0 & 1945 & 2 & 1965 & 1 & 1985 & 3 & 2005 & 5 \\
\hline 1906 & 3 & 1926 & 3 & 1946 & 1 & 1966 & 2 & 1986 & 0 & 2006 & 0 \\
\hline 1907 & 0 & 1927 & 0 & 1947 & 2 & 1967 & 0 & 1987 & 1 & 2007 & 0 \\
\hline 1908 & 0 & 1928 & 2 & 1948 & 2 & 1968 & 2 & 1988 & 0 & 2008 & 2 \\
\hline 1909 & 2 & 1929 & 1 & 1949 & 1 & 1969 & 2 & 1989 & 0 & 2009 & 0 \\
\hline 1910 & 1 & 1930 & 0 & 1950 & 5 & 1970 & 0 & 1990 & 0 & 2010 & 0 \\
\hline 1911 & 2 & 1931 & 0 & 1951 & 1 & 1971 & 0 & 1991 & 2 & & \\
\hline 1912 & 1 & 1932 & 2 & 1952 & 1 & 1972 & 1 & 1992 & 1 & & \\
\hline 1913 & 0 & 1933 & 5 & 1953 & 2 & 1973 & 0 & 1993 & 0 & & \\
\hline 1914 & 0 & 1934 & 1 & 1954 & 2 & 1974 & 0 & 1994 & 0 & & \\
\hline 1915 & 2 & 1935 & 2 & 1955 & 0 & 1975 & 1 & 1995 & 3 & & \\
\hline 1916 & 3 & 1936 & 1 & 1956 & 2 & 1976 & 0 & 1996 & 2 & & \\
\hline 1917 & 1 & 1937 & 0 & 1957 & 0 & 1977 & 0 & 1997 & 1 & & \\
\hline 1918 & 0 & 1938 & 0 & 1958 & 1 & 1978 & 0 & 1998 & 2 & & \\
\hline 1919 & 1 & 1939 & 1 & 1959 & 2 & 1979 & 2 & 1999 & 3 & & \\
\hline 1920 & 1 & 1940 & 1 & 1960 & 1 & 1980 & 0 & 2000 & 1 & & \\
\hline
\end{tabular}

Historical data are retrieved and denoted by $X=\left\{x_{i}\right\}(I=1,2, \ldots, N)$, where $N=110$ is the number of years of data available and $x_{i}$ is the number of storms occurred in the $i$ th year. Values of $x$ range in between 0 and 5 with mean 1.1091 and standard deviation 1.1704 (Table 2).

Table 2. Descriptive Statistics of Annual Occurrence Rate

\begin{tabular}{|lcll|}
\hline Sample size $(N)$ & 110 & Min & 0 \\
Mean & 1.1091 & Median & 1 \\
Variance & 1.3699 & Max & 5 \\
Std. deviation & 1.1704 & Range & 5 \\
\hline
\end{tabular}

Each storm is considered as a point event in time, occurring independently. If $\lambda$ is a measure of the historically determined number of events per year, then the probability 
$\mathrm{P}(X=x \mid \lambda)$ defines the probability of having $x$ events per year, which is given by the Poisson probability density function (PDF)

$$
P(x)=\frac{\lambda^{x}}{x !} e^{-\lambda} .
$$

The parameter of the Poisson distribution $\lambda$ can be estimated from data by the maximum likelihood estimator

$$
\hat{\lambda}=\frac{\sum_{i=1}^{N} x_{i}}{N} .
$$

The Negative Binomial distribution PDF is given by

$$
P(x)=\frac{\Gamma(x+k)}{\Gamma(x+1) \Gamma(k)}\left(\frac{k}{m+k}\right)^{k}\left(\frac{m}{m+k}\right)^{x},
$$

where $\Gamma$ is the gamma function, $m$ and $k$ are parameters of the distribution. The maximum likelihood estimates of parameters can be obtained as

$$
\widehat{m}=\frac{\sum_{i=1}^{N} x_{i}}{N} \text { and } \hat{k}=\frac{\widehat{m}^{2}}{s^{2}-\widehat{m}},
$$

where $s^{2}$ is the sample variance.

The parameters of both Poisson and Negative Binomial distributions were estimated using annual number of hurricanes dataset and results are presented in Table 3 .

Table 3. Estimated distribution parameters for $A H O$ data

\begin{tabular}{|ll|}
\hline \multicolumn{1}{|c|}{ Year } & Total hurricanes \\
\hline $\begin{array}{l}\text { Poisson } \\
\text { Negative Binomial }\end{array}$ & $\lambda=1.1091$ \\
& $n=4, p=0.8096$ \\
\hline
\end{tabular}

After the estimation of parameters of both Poisson and Negative Binomial distributions, goodness-of-fit tests are performed to select the best fitting model.

The Kolmogorov-Smirnov test is used to decide if a sample comes from a hypothesized continuous distribution. It is derived from the empirical cumulative 
distribution function (CDF). Assume that we have a random sample $x_{1}, x_{2}, \ldots, x_{\mathrm{n}}$ from some distribution with $\mathrm{CDF} F(x)$. The empirical CDF is denoted by

$$
F_{n}(x)=\frac{\text { Number of observations } \leq x}{n} .
$$

The Kolmogorov-Smirnov statistic $(D)$ is derived from the largest vertical difference between the theoretical $\left(F\left(x_{i}\right)\right)$ and the empirical cumulative distribution function:

$$
D=\max _{1 \leq i \leq n}\left(F\left(x_{i}\right)-\frac{i-1}{n}, \frac{i}{n}-F\left(x_{i}\right)\right) .
$$

The Kolmogorov-Smirnov statistic is thus only concerned with the maximum vertical distance between the cumulative distribution function of the fitted distribution and the cumulative distribution of the data. The Kolmogorov-Smirnov statistic's value is only determined by the one largest discrepancy and takes no account of the lack of fit across the rest of the distribution.

The null and the alternative hypotheses are: $\mathrm{H}_{0}$ : the data follow the specified distribution vs. $\mathrm{H}_{\mathrm{A}}$ : the data do not follow the specified distribution. The P-value is calculated from the test statistic, and denotes the threshold value of the significance level in the sense that the null hypothesis $\left(\mathrm{H}_{0}\right)$ will be accepted for all values of $\alpha$ less than the P-value.

The Anderson-Darling test compares the fit of an observed cumulative distribution function to an expected cumulative distribution function. The A-D test gives more weight to the tails than the Kolmogorov-Smirnov test.

The Anderson-Darling statistic $\left(A^{2}\right)$ is defined as 


$$
A^{2}=-n-\frac{1}{n} \sum_{i=1}^{n}(2 i-1) \times\left[\ln F\left(x_{i}\right)+\ln \left(1-F\left(x_{n-i+1}\right)\right)\right] .
$$

The Chi-Square $\left(\chi^{2}\right)$ goodness-of-fit test measures how well the expected frequency of the fitted distribution compares with the observed frequency of a histogram of the observed data.

The Chi Square statistic is calculated as follows:

$$
\chi^{2}=\sum_{i=1}^{N} \frac{\left(O_{i}-E_{i}\right)^{2}}{E_{i}}
$$

where $O_{i}$ is the observed frequency of the $i$ th histogram class or bar and $E_{i}$ is the expected frequency from the fitted distribution for the $i$ th histogram bar.

Since the $\chi^{2}$ statistic sums the squares of all of the errors it can be disproportionately sensitive to any large errors. The $\chi^{2}$ statistic is also very dependent on the number of bars $N$ that are used and by changing the number of bars one can quite easily switch ranking between two distribution types.

\begin{tabular}{|c|c|c|c|c|c|c|c|}
\hline \multirow{2}{*}{ Distribution } & \multicolumn{3}{|c|}{ Chi-Squared } & \multicolumn{2}{|c|}{ Kolmogorov-Smirnov } & \multicolumn{2}{|c|}{ Anderson-Darling } \\
\hline & Statistic & P-value & Rank & Statistic & Rank & Statistic & Rank \\
\hline Poisson & 1.71979 & 0.88640 & 1 & 0.32986 & 1 & 16.465 & 1 \\
\hline Neg. Binomial & 2.83815 & 0.58527 & 2 & 0.42963 & 2 & 28.094 & 2 \\
\hline
\end{tabular}

Table 4. Goodness-of-fit tests for $A H O$ data

The results of goodness-of-fit tests for both Poisson and Negative Binomial distributions are presented in Table 4 and according to all 3 tests, the Poisson distribution is showing a better fit than Negative Binomial.

For visual assessment and an empirical comparison of the goodness of fit the distribution graphs can be used. Figure 6 shows the occurrence rates of historical and 
modeled hurricane data. Poisson model does appear to have a better agreement with historical occurrences than the Negative Binomial.

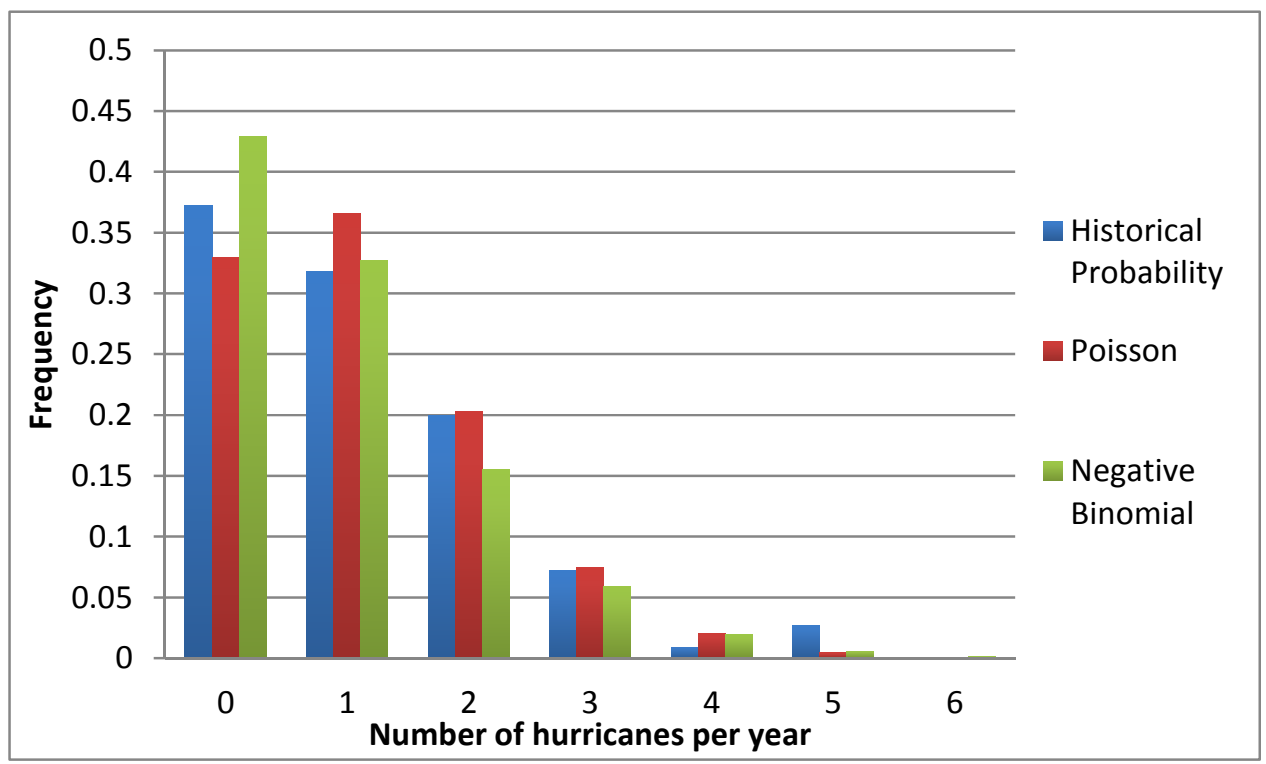

Figure 6. Comparison of simulated vs. historical occurrences

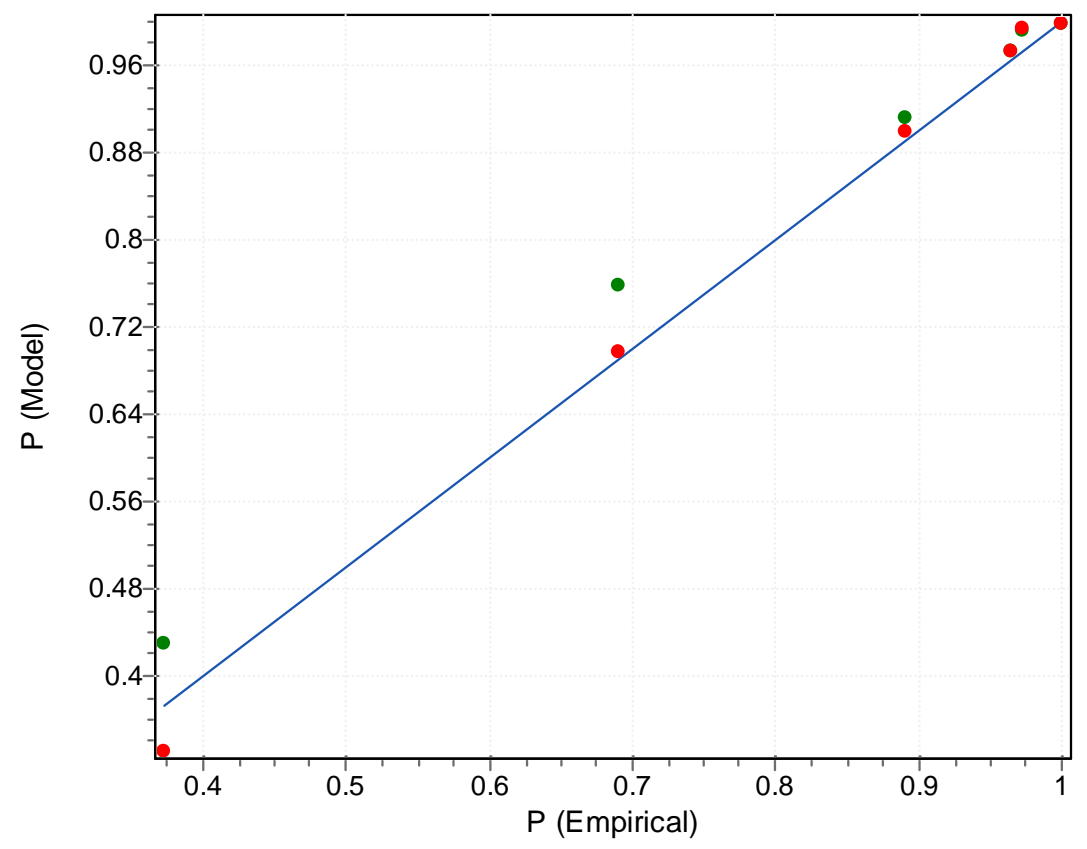

- Neg. Binomial • Poisson

Figure 7. P-P plot 
In order to see how well Poisson and Negative Binomial Distributions fit AHO data we can also look at the P-P plot (Figure 7), which is a graph of the empirical CDF values plotted against the fitted CDF values and the closer to linear it is, the better the distribution fits the data. Points of the Poisson distribution are closer to the straight line than the Negative Binomial which means that the Poisson distribution is the better choice for AHO model. This is consistent with the goodness-of-fit tests.

I conclude that the best fitting distribution for the annual hurricane occurrence on the basis of the results of goodness-of-fit tests, histogram of historical and modeled occurrences and P-P plot is Poisson distribution with parameter $\lambda=1.1091$. 


\section{RADIUS OF MAXIMUM WINDS}

The next part of the atmospheric science component of the hurricane model is the wind field model. Here hurricanes are simulated using historical data in order to record wind speeds and decay of the storm once on land. Recorded data from the wind field model are later used by engineers and actuarial scientists in assessment of the likely damage to insured property and losses associated with it.

Radius of maximum winds $\left(R_{\max }\right)$ is one of the random variables used to characterize the wind field. The radius of maximum winds at landfall is the distance between the center of a cyclone and its band of strongest winds. I am going to look closely at $R_{\max }$ and select a statistical distribution that is best for describing $R_{\max }$.

The statistical information used to develop an $R_{\max }$ model (landfall $R_{\max }$ database) is created using the historical record for the Atlantic tropical cyclone basin (known as "HURDAT") and applying the annual occurrence model and the storm track model. The database includes 112 measurements of radius of maximum wind, central pressure and location at landfall for storms from 1901 till 2010 (Appendix 1).

Values of $R_{\max }$, measured in statue miles, range in between 5.75 and 52.9 with mean 25.65 and standard deviation 11.2 (Table 5).

Table 5. Descriptive Statistics of Radius of Maximum Winds

\begin{tabular}{|llr|}
\hline Sample size & 112 Min & 5.75 \\
Mean & 25.649 Median & 24.725 \\
Variance & 125.31 Max & 52.9 \\
Std. deviation & 11.194 Range & 47.15 \\
\hline
\end{tabular}

There are numerous probability distributions each developed to address various data analysis needs, therefore the candidate distributions to fit should be chosen 
according to the nature of the data. The $R_{\max }$ dataset is continuous. Another way to classify the distributions considers the range. Radius of maximum winds cannot contain negative values so only non-negative distributions should be considered.

Another way of identifying the proper distribution is by looking at the histogram of the data and determining whether the data are symmetric, left-skewed, right-skewed and using the distributions which have the same shape. According to the histogram the $R_{\max }$ data are right-skewed (Figure 8).

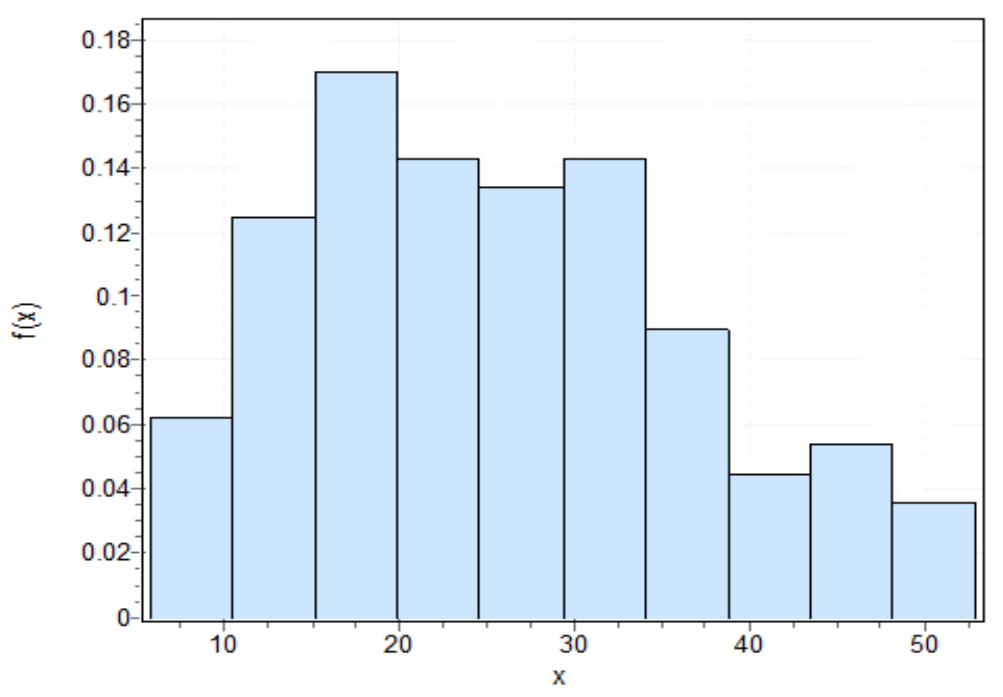

Figure 8. Probability Density Function of Radius of Maximum Winds

Using EasyFit software I have done preliminary analysis of the $R_{\max }$ landfall database on the basis of its semiboundness and skewness. Only distributions with maximum of 2 parameters were considered because extra parameters will make the use for the wind field model over complicated and not practical. Also distributions with more parameters may well fit the data better because of a lot more flexibility in shape than a 2parameter and apparent improvement may be spurious due to over-fitting. 
Five distributions that were found to be a good fit for modeling $R_{\max }$ on the basis of the provided criteria: Gamma, Lognormal, Rayleigh, Weibull and Inverse Gaussian. Gamma and Lognormal are the distributions that were considered in the Florida Public Hurricane Loss Model and Gamma was chosen as the best fit. Probability density functions of selected distributions are presented in the table (Table 6).

Table 6. Probability density functions of distributions to be fitted to $R_{\max }$ data

\begin{tabular}{|c|c|c|}
\hline Gamma & $f(x)=\frac{x^{\alpha-1}}{\beta^{\alpha} \Gamma(\alpha)} e^{-\frac{x}{\beta}}$ & $\begin{array}{c}0 \leq x \leq+\infty \\
\alpha>0, \quad \beta>0\end{array}$ \\
\hline Lognormal & $f(x)=\frac{e^{-\frac{1}{2}\left(\frac{\ln x-\mu}{\delta}\right)^{2}}}{x \delta \sqrt{2 \pi}}$ & $\begin{array}{c}0 \leq x \leq+\infty \\
\delta>0\end{array}$ \\
\hline Rayleigh & $f(x)=\frac{x-\gamma}{\delta^{2}} e^{-\frac{1}{2}\left(\frac{x-\gamma}{\delta}\right)^{2}}$ & $\begin{array}{c}\gamma \leq x \leq+\infty \\
\delta>0\end{array}$ \\
\hline Weibull & $f(x)=\frac{\alpha}{\beta}\left(\frac{x}{\beta}\right)^{\alpha-1} e^{-\left(\frac{x}{\beta}\right)^{\alpha}}$ & $\begin{array}{c}0 \leq x \leq+\infty \\
\alpha>0, \quad \beta>0\end{array}$ \\
\hline Inverse Gaussian & $f(x)=\sqrt{\frac{\lambda}{2 \pi x^{3}}} e^{\left(-\frac{\lambda(x-\mu)^{2}}{2 \mu^{2} x}\right)}$ & $\begin{array}{c}0 \leq x \leq+\infty \\
\lambda>0, \quad \mu>0\end{array}$ \\
\hline
\end{tabular}

Parameters of selected distributions were obtained using maximum likelihood estimators and results are presented in the table (Table 7).

Table 7. Estimated distribution parameters for $R_{\max }$ data

\begin{tabular}{|ll|}
\hline Distribution & Parameters \\
\hline Gamma & $\alpha=5.2501, \beta=4.8855$ \\
\hline Lognormal & $\delta=0.49202, \mu=3.1363$ \\
\hline Weibull & $\alpha=2.4736, \beta=28.666$ \\
\hline Rayleigh & $\delta=17.293, \gamma=3.8794$ \\
\hline Inverse Gaussian & $\lambda=134.66, \mu=25.65$ \\
\hline
\end{tabular}


In order to determine how well the selected distributions fit the $R_{\max }$ data I have tested them for a goodness-of-fit and the results are presented in Table 8.

Table 8. Goodness-of-fit tests for $R_{\max }$ data

\begin{tabular}{|l|r|r|r|r|r|}
\hline \multicolumn{1}{|c|}{ Distribution } & \multicolumn{2}{|c|}{ Kolmogorov-Smirnov } & \multicolumn{2}{|c|}{ Anderson-Darling } \\
\hline Weibull & Statistic & P-value & Rank & Statistic & Rank \\
\hline Rayleigh & 0.04939 & 0.93492 & 1 & 0.32264 & 2 \\
\hline Gamma & 0.05608 & 0.85301 & 2 & 0.30063 & 1 \\
\hline Lognormal & 0.07027 & 0.61237 & 3 & 0.5349 & 3 \\
\hline Inverse Gaussian & 0.0953 & 0.30146 & 4 & 1.0419 & 4 \\
\hline
\end{tabular}

The idea behind the goodness-of-fit tests is to measure the distance between the data and the tested distribution. And although the logic of applying various goodness-offit tests is the same, they differ in how the test statistic is calculated. The most commonly used goodness of fit tests are Kolmogorov-Smirnov, Anderson-Darling and Chi-Square. The two goodness-of-fit tests that were used are Kolmogorov-Smirnov and AndersonDarling. The chi-square test is not considered because the test has low power for continuous data.

The Kolmogorov-Smirnov test was used to arrange the distributions in the order of performance according to that test. Since the goodness-of-fit test statistics indicate the distance between the data and the fitted distributions, it is obvious that the distribution with the lowest statistic value is the best fitting. 
Lognormal and Inverse Gaussian distributions show poor fit for $R_{\max }$ data with Pvalues of Kolmogorov-Smirnov test below 0.5. Other distributions show better fits according to both Kolmogorov-Smirnov and Anderson-Darling tests. I conclude that Lognormal and Inverse Gaussian distributions are not good fits and exclude them from further consideration.

The three distributions for be considered further are Weibull, Rayleigh and Gamma. Gamma distribution was used to fit the radius of maximum winds in the Florida Public Hurricane Loss Evaluation Model, however we see that other distributions perform better than the Gamma distribution.

Along with the goodness of fit tests, the distribution graphs can be very helpful to determine the best fitting model. They enable us to visually assess the goodness of fit and empirically compare several fitted models.

First I consider the Probability Density Function Graph which displays the theoretical PDFs of the fitted distributions and the histogram of the $R_{\max }$ data (Figures 9 and 10). Since the histogram depends on how the data are sorted into bins, two histograms are displayed with the $R_{\max }$ values binned in 10 and 15 intervals for comparative analysis. All 3 distributions are plotted on the same graphs. Displaying several distributions at the same time will allow us to visually compare the models and determine how they differ.

Although it can be difficult to come to a decision about better fit on the basis of these graphs as they require the arbitrary grouping of the data, the Weibull and Rayleigh distributions do appear to fit data better that the Gamma distribution. 


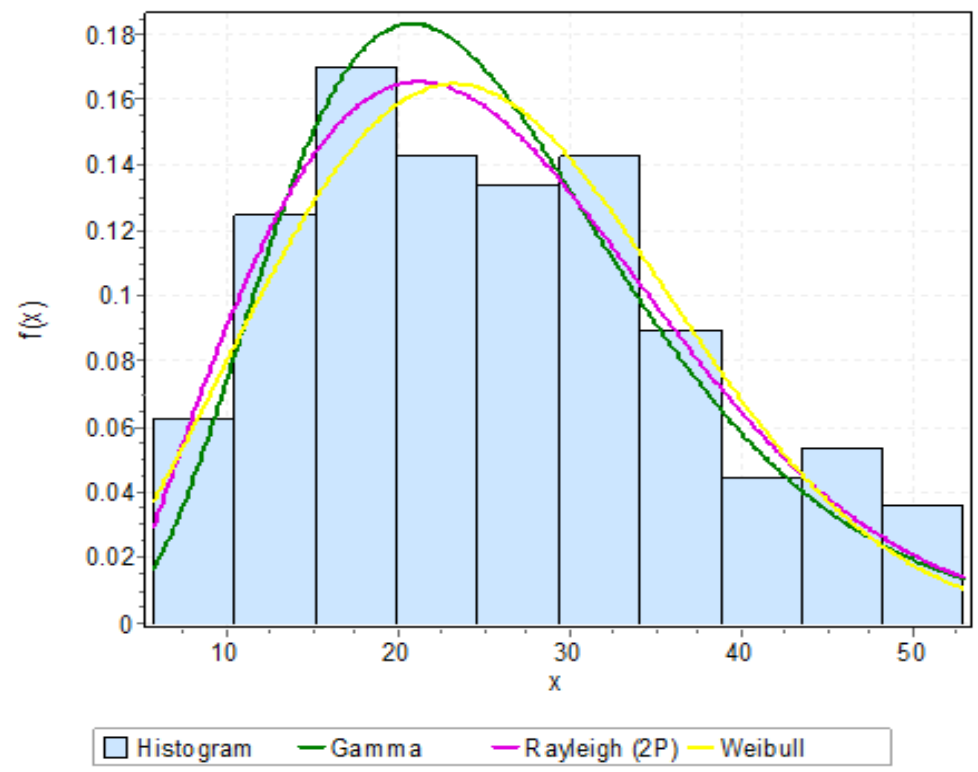

Figure 9. PDF Graph with Rmax values binned in 10 intervals

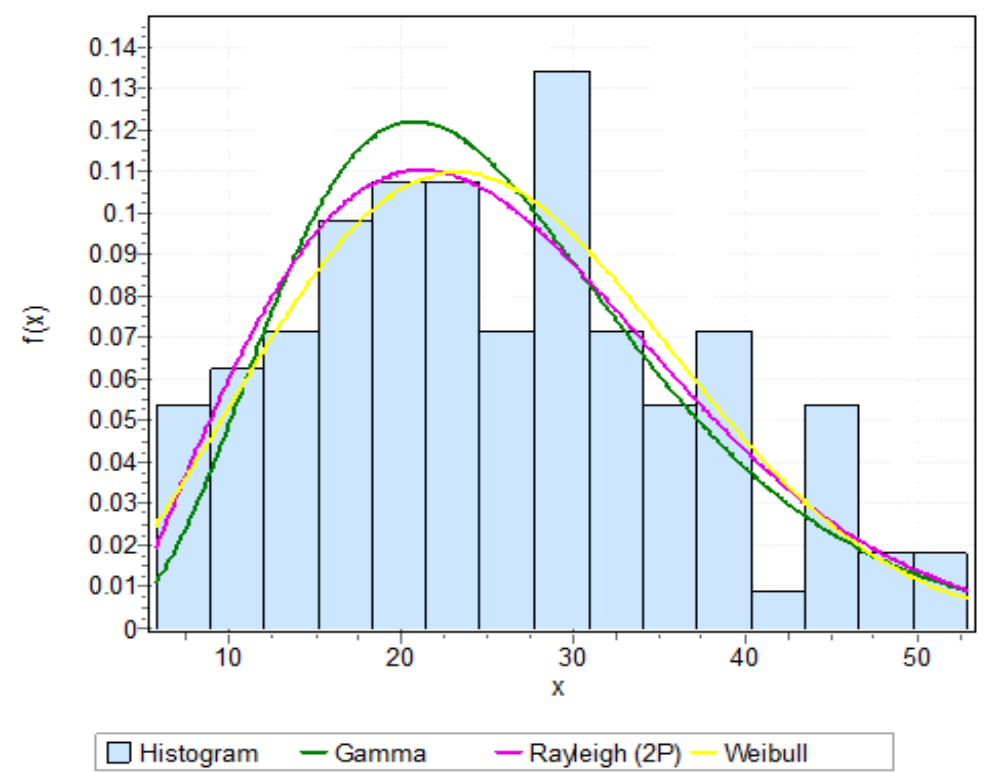

Figure 10. PDF Graph with Rmax values binned in 15 intervals

To avoid grouping of the data we can look at the Q-Q plot (Figure 11). In the quantile-quantile graph the input data values are plotted against the quantiles of the fitted distribution and both axes of this graph are in statue miles - units of the Rmax. Weibull, Rayleigh and Gamma distributions are plotted on the same plot. 
Figure 11. Q-Q plot

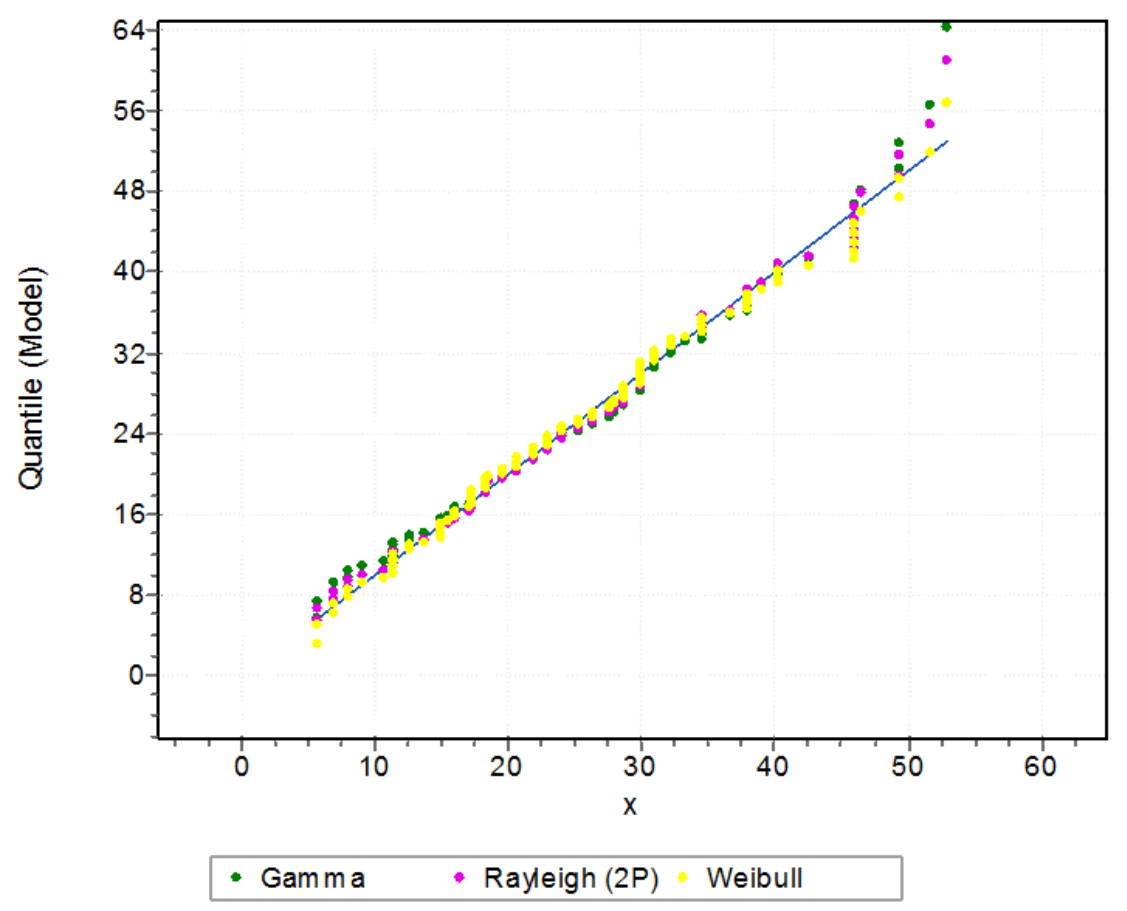

If the distribution is the correct model, the graph points will lie on an approximately straight line. All 3 distributions have Q-Q plots that make us believe that they are good fits but Gamma and Rayleigh distributions have points further away from the straight line as values of $R_{\max }$ get larger. This is consistent with the results of the Kolmogorov-Smirnov test.

On the basis of the results of Goodness-of-fit test, the Probability Density Function Graph and the Q-Q plot, the Weibull distribution with parameters $\alpha=2.4736$ and $\beta=28.666$ is the best fit for the Radius of maximum winds.

Gamma and Weibull distributions are commonly encountered in reliability analysis and it is often difficult to choose between the two. Nevertheless, as explained by Bain and Engelhardt (1980), "even though the two models may offer similar data fits even for moderate sample sizes, it is still desirable to select the correct (or more nearly 
correct) model, if possible, since inferences based on the model will often involve tail probabilities where the affect of the model assumption will be more critical”.

Although the Gamma distribution cannot be rejected for modeling $R_{\max }$ in the wind field model, I show that the Weibull distribution is a better fit for the radius of maximum winds. 


\section{HOLLAND B}

Another important parameter of the wind field model is the Holland $B$ parameter. Holland $B$ is an additional parameter defining the pressure field and maximum wind speeds in a hurricane. It was introduced by Holland in 1980 and since been used in hurricane threat studies by many researchers including Powell et al. (2005), James and Mason (2005), Emanuel et al. (2006), Lee and Rosowsky (2007), Hall and Jewson (2008) and Vickery et al. (2009) among others.

The pressure $p(r)$ is defined as:

$$
p(r)=p_{c}+\Delta p e^{-\left(\frac{R_{\max }}{r}\right)^{B}}
$$

where $r$ is the distance from the center of the storm, $p_{c}$ is the pressure at the center of the storm, $\Delta p$ is the difference between central minimum sea level pressure $\left(p_{c}\right)$ and an outer peripheral pressure (1013 mb), and $R_{\max }$ is the radius of maximum winds.

Introduction of $B$ parameter results in the maximum wind speed in the simulated hurricane be proportional to $\sqrt{B \Delta p}$ compared to $\sqrt{\Delta p}$ without the Holland $B$.

A model for the Holland B pressure profile parameter will be developed using a subset of the data published by Willoughby and Rahn (2004). Data consist of winds and geopotential heights obtained by NOAA and U.S. Air Force Reserve aircraft between 1977 and 2000 and supplemented with $\Delta p$ pressure deficit and $R_{\max }$ values. We retained 116 profiles with latitudes $20^{\circ}-34^{\circ} \mathrm{N}$, longitudes $70^{\circ}-95^{\circ} \mathrm{W}$, flight level winds $V_{\max }$ $>30 \mathrm{~m} / \mathrm{s}$ and values of $B$ 0.5-2.2 (Appendix 2).

Least squares fits of the Holland $B$ model to the data will offer assessment of the parameters' distributions. 
The FHPLM considers 2 models: in first model Holland $B$ is correlated with the radius of maximum winds $\left(R_{\max }\right)$ and latitude of the hurricane (Lat)

$$
B=\beta_{0}+\beta_{1} L a t+\beta_{2} R_{\max }+\varepsilon,
$$

in the second model, the $B$ parameter is also correlated with $\Delta p^{2}$ the square difference between central minimum sea level pressure and an outer peripheral pressure (1013 mb)

$$
B=\beta_{0}+\beta_{1} \text { Lat }+\beta_{2} R_{\max }+\beta_{3} \Delta p^{2}+\varepsilon \text {. }
$$

Multiple regression analysis was performed on the dataset using the Proc REG procedure in SAS (Appendix 3A). On the basis of the least squares parameter estimates (Appendix 4A) the model for estimation of Holland $B$ using the radius of maximum winds and latitude of the hurricane is:

$$
\widehat{B}=1.55384+0.00015058 \text { Lat }-0.00439 R_{\max }
$$

Testing for significance of the regression equation using ANOVA (Appendix 4A) showed $\mathrm{F}=7.14$ with $\mathrm{P}$-value $=0.0012$, which means this regression is significant.

Coefficient of determination $\mathrm{R}^{2}=0.1121$, which means that only $11.21 \%$ of the total variability in the $B$ parameter is explained by the fitted equation.

Similar regression analysis was performed on the model for estimation of Holland $B$ using the radius of maximum winds, latitude of the hurricane and the square difference between central minimum sea level pressure and an outer peripheral pressure using the Proc REG procedure in SAS (Appendix 3B). On the basis of the least squares parameter estimates (Appendix 4B) the new model is:

$$
\widehat{B}=1.50264+0.00086116 L a t-0.00423 R_{\max }+0.00000885 \Delta p^{2} .
$$

Testing for significance of the regression equation using ANOVA (Appendix 4B) showed $\mathrm{F}=4.95$ with $\mathrm{P}$-value $=0.0029$, which means this regression is significant. 
Coefficient of determination $\mathrm{R}^{2}=0.1171$, which means that only $11.71 \%$ of the total variability in the $B$ parameter is explained by the fitted equation. Model including $\Delta p^{2}$ has a slightly higher coefficient of determination but still does not explain most of variability in Holland $B$.

In order to obtain a model which can explain a larger portion of variability in Holland $B$ parameter we can include all available predictor variables in the regression model:

$$
B=\beta_{0}+\beta_{1} \text { Lat }+\beta_{2} \text { Lon }+\beta_{3} R_{\max }+\beta_{4} \Delta p^{2}+\beta_{5} V_{\text {max }}+\varepsilon,
$$

where Lat is the latitude of the hurricane, Lon is the longitude of the hurricane, $R_{\max }$ is the radius of maximum winds, $\Delta p^{2}$ is the square difference between central minimum sea level pressure and an outer peripheral pressure $(1013 \mathrm{mb}), V_{\max }$ is the maximum wind and $\varepsilon$ is the error term.

Using SAS Proc REG procedure (Appendix 3C) multiple regression analysis was performed. On the basis of the least squares parameter estimates (Appendix 4C) the model for estimation Holland $B$ using all available predictor variables is:

$$
\begin{gathered}
\widehat{B}=0.25712-0.001 \text { Lat }-0.00308 \text { Lon }-0.00157 R_{\max }-0.00006305 \Delta p^{2}+ \\
0.02652 V_{\max } .
\end{gathered}
$$

Testing for significance of the regression equation using ANOVA (Appendix 4C) showed $\mathrm{F}=13.17$ with $\mathrm{P}$-value $<0.0001$, which means this regression is significant.

Coefficient of determination in this case $\mathrm{R}^{2}=0.3745$, which is significantly higher than the previous two models and means that $37.45 \%$ of the total variability in the $B$ parameter is explained by the fitted equation. 
Although this model is good it is not convenient. The model includes terms with large individual t-test p-values: P-value $($ Lat $)=0.877$ and $\mathrm{P}$-value $($ Lon $)=0.337$ (Appendix 4C). This suggests that perhaps the model is more complicated than it needs to be and includes some redundant terms. We should check if it can be reduced. In order to simplify the model a stepwise procedure on the basis of the partial F-value was chosen and performed on the dataset using the Proc Stepwise in SAS (Appendix 3C). Obtained results (Table 9) suggest the following optimal reduced model:

$$
\widehat{B}=\beta_{0}+\beta_{1} R_{\text {max }}+\beta_{2} \Delta p^{2}+\beta_{3} V_{\text {max }}+\varepsilon .
$$

Table 9. Results of the stepwise procedure

\begin{tabular}{|r|l|l|r|r|r|r|r|r|}
\hline \multicolumn{7}{|c|}{ Summary of Stepwise Selection } \\
\hline Step & $\begin{array}{l}\text { Variable } \\
\text { Entered }\end{array}$ & $\begin{array}{l}\text { Variable } \\
\text { Removed }\end{array}$ & $\begin{array}{r}\text { Number } \\
\text { Vars In }\end{array}$ & $\begin{array}{r}\text { Partial } \\
\text { R-Square }\end{array}$ & $\begin{array}{r}\text { Model } \\
\text { R-Square }\end{array}$ & C(p) & F Value & Pr > F \\
\hline $\mathbf{1}$ & vmax & 1 & 0.2277 & 0.2277 & 23.8152 & 33.60 & $<.0001$ \\
\hline 2 & delp2 & 2 & 0.1249 & 0.3525 & 3.8546 & 21.80 & $<.0001$ \\
\hline 3 & rmax & 3 & 0.0163 & 0.3689 & 2.9842 & 2.90 & 0.0915 \\
\hline
\end{tabular}

On the basis of the least squares parameter estimates obtained using SAS multiple regression analysis (Appendix 3D, 4D) the model for estimation Holland $B$ using $R_{\max }$ the radius of maximum winds, $\Delta p^{2}$ the square difference between central minimum sea level pressure and an outer peripheral pressure $(1013 \mathrm{mb})$ and $V_{\max }$ the maximum wind is:

$$
\widehat{B}=0.50274-0.00181 R_{\max }-0.00006228 \Delta p^{2}+0.02612 V_{\max }
$$

Removing two indicators from the model increased the value of adjusted $\mathrm{R}_{\mathrm{A}}{ }^{2}$ to 0.3520 compared to 0.3460 for the model with five predictors. Unlike $\mathrm{R}^{2}$, the adjusted $\mathrm{R}_{\mathrm{A}}{ }^{2}$ increases only if the new term improves the model more than would be expected by 
chance. Compared to the full model coefficient of determination $\mathrm{R}^{2}$ was reduces from 0.3745 to 0.3689 , which is still significantly higher than the first two models.

Throughout my analysis I have assumed that the errors are normally and independently distributed with mean zero and constant variance $\sigma^{2}$ as well as that the observations are adequately described by the model. Residual analysis is the key tool in model adequacy checking. The most effective method of checking the normality assumption is constructing a normal probability plot of the residuals. If the errors are normally distributed this plot should resemble a straight line. While investigating this plot the focus should be on the central values of the plot rather than the extremes. The normal probability plot of the residuals for Holland $B$ with $R_{\max }, \Delta p^{2}$ and $V_{\max }$ as predictors (Figure 12) resembles a straight line with all values being in $(-2.7,2.7) \mathrm{z}$ - range.

Figure 12. Normal Probability Plot

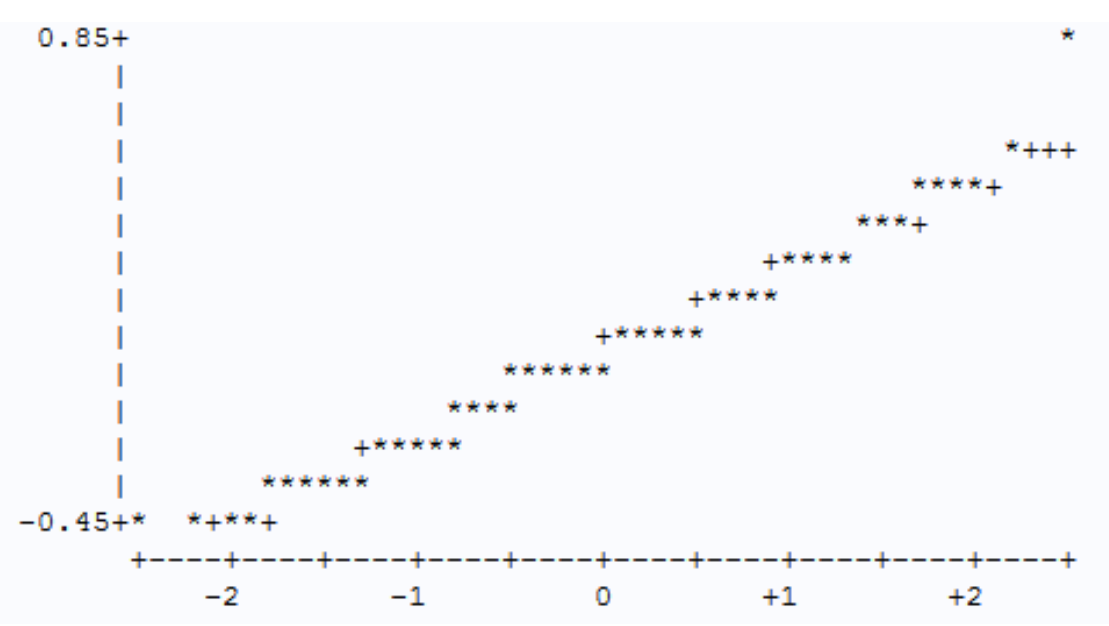

Plot of residuals vs. predicted values (Figure 13) does not reveal any obvious patterns. Data are scattered randomly around 0. This supports the assumption that the error distribution for Holland $B$ with $R_{\max }, \Delta p^{2}$ and $V_{\max }$ as predictors is approximately normal. 


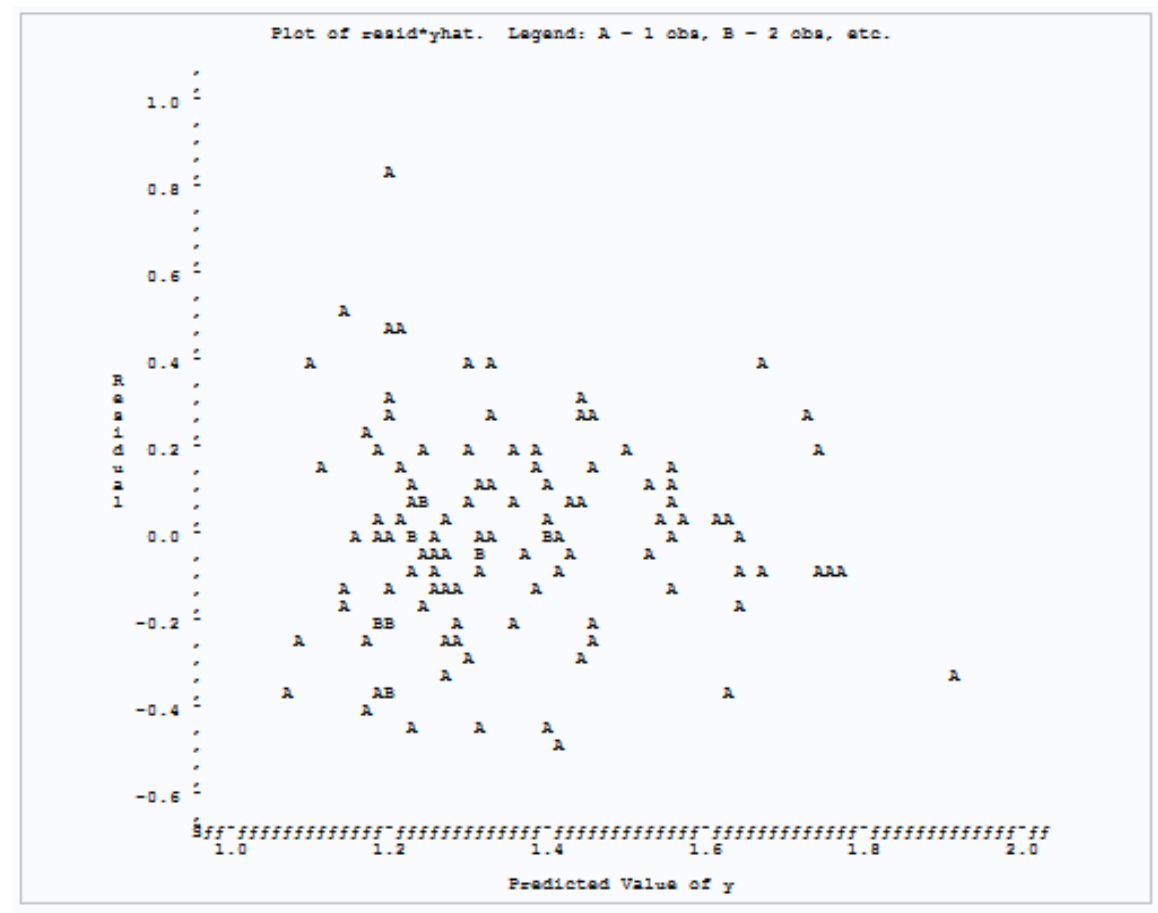

Figure 13. Plot of Residuals vs. Predicted values

Four models for Holland $B$ parameter were considered. First two models, both used in the FHPLM, could only explain $11.21 \%$ and $11.71 \%$ of the total variability in the $B$ parameter. The first model used the radius of maximum winds and the latitude of the hurricane and predictor variables; the second model also considered the square difference between central minimum sea level pressure and an outer peripheral pressure. The third model explained $37.45 \%$ of the total variability in Holland $B$ but included five predictor variables. The fourth model was chosen to be the most optimal for use in predicting the Holland $B$ parameter. It explains $36.89 \%$ of the total variability in the predicted parameter and correlated Holland $B$ with the radius of maximum winds, the square difference between central minimum sea level pressure and an outer peripheral pressure and the maximum wind:

$$
\widehat{B}=0.50274-0.00181 R_{\max }-0.00006228 \Delta p^{2}+0.02612 V_{\max }
$$




\section{FINAL RESULTS AND CONCLUSIONS}

The FPHLM is the only open public hurricane loss evaluation model available for assessment of hazard to insured residential property related to damage from hurricanes in Florida. Atmospheric science component is the first part of this model; it simulates thousands of storms, their wind speeds and their decay once on land on the basis of historical hurricane statistics defining wind risk for all residential zip codes in Florida.

The focus of my thesis was to analyze the atmospheric science component of the Florida Public Hurricane Loss Model, replicate statistical procedures used to model various parameters of atmospheric component and to validate the model.

First I looked at the available data from the time point prospective and checked for increasing trends in hurricane intensity, size or number of hurricanes striking Florida. The time series of annual hurricane counts, the plot of radius of maximum winds in time or the plot of central pressure in time show no visible patterns in the data and nothing suggests an increasing trend. My findings do not support the argument that global tropical cyclone intensity, frequency and longevity have undergone increases in the recent years. I concluded that no significant increasing trend is evident.

Next I studied the frequency with which hurricanes occur and generated statistical distribution from the available historical data in order to estimate annual hurricane occurrence. Two distributions were considered: Poisson and Negative Binomial. On the basis of the results of goodness-of-fit tests, histograms of historical and modeled occurrences and P-P plots, I concluded that the best fitting distribution for the annual hurricane occurrence is the Poisson distribution with parameter $\lambda=1.1091$. 
Further I modeled the distribution of radius of maximum winds which is a critical parameter for estimating the possible losses for insurance pricing purposes. The radius of maximum winds has a substantial impact on the area affected by hurricane and modeling of the $R_{\max }$ influences the likelihood of the location experiencing strong winds in cases of near misses. Five distributions were considered: Gamma, Lognormal, Rayleigh, Weibull and Inverse Gaussian. On the basis of the results of the Goodness-of-fit test, Probability Density Function Graph and the Q-Q plot, the Weibull distribution with parameters $\alpha=2.4736$ and $\beta=28.666$ was chosen as the best fit for the Radius of maximum winds. The FPHLM currently uses Gamma distribution for modeling radius of maximum winds and although the Gamma distribution cannot be rejected for modeling $R_{\max }$ in the wind field model, I showed that the Weibull distribution is better fit.

Finally, the expression for finding an exact statistical relationship between the pressure profile parameter Holland and its' predictor variables was computed. Four models for the Holland $B$ parameter were considered. The first two models, both considered in the FHPLM, could only explain $11.21 \%$ and $11.71 \%$ of the total variability in the $B$ parameter. The third model explained $37.45 \%$ of the total variability in Holland $B$ but included five predictor variables. The fourth model was chosen to be the most optimal to use in predicting Holland $B$ parameter. It explains $36.89 \%$ of the total variability in the predicted parameter and correlated Holland $B$ with the radius of maximum winds, the square difference between central minimum sea level pressure and an outer peripheral pressure and the maximum wind: $\widehat{B}=0.50274-0.00181 R_{\max }-$ $0.00006228 \Delta p^{2}+0.02612 V_{\max }$. 


\section{REFERENCES}

L.J. Bain, M. Engelhardt, "Probability of correct selection of Weibull versus gamma based on likelihood ratio", Communications in Statistics - Theory and Methods, A9, p. $375-381,1980$.

S.-C. Chen, S. Gulati, S. Hamid, X. Huang, L. Luo, N. Morisseau-Leroy, M. Powell, C. Zhan, C. Zhang, "A three-tier system architecture design and development for hurricane occurrence simulation", Proc. of the IEEE Int. Conference on Information Technology: Research and Education, 2003.

S.-C. Chen, S. Gulati, S. Hamid, X. Huang, L. Luo, N. Morisseau-Leroy, M. Powell, C. Zhan, C. Zhang, "A Web-based distributed system for hurricane occurrence projection", Software - Practice and Experience, vol.34, 2004.

J.B. Elsner, S.C. Schmertmann, "Improving Extended-range Seasonal Predictions of Intense Atlantic Hurricane Activity”, Weather Forecasting, vol. 8, p. 345-351, 1993.

J.B. Elsner, T.H. Jagger, "A Hierarchical Bayesian Approach to Seasonal Hurricane Modeling”, J. Climate, vol. 17, p. 2813-2827, 2004.

K.A. Emanuel, "Increasing destructiveness of tropical cyclones over the past 30 years”, Nature, vol. 326, p. 686-688, 2005.

K.A. Emanuel, S. Ravela, E. Vivant, C. Risi, "A Statistical-Deterministic Approach to Hurricane Risk Assessment", Bulletin of the American Meteorological Society, vol. 19, p. 299-314, 2006.

W.M. Gray, C.W. Landsea, P.W. Mielke Jr., K.J. Berry, "Predicting Atlantic Seasonal Hurricane Activity 6-11 Months in Advance", Weather Forecasting, vol. 7, p. 440-455, 1992.

T. Hall, S. Jewson, "Comparison of Local and Basin-wide Methods for Risk Assessment of Tropical Cyclone Landfall”, Journal of Applied Meteorology and Climatology, vol. 47, p. 361-367, 2008.

S. Hamid, G. Kibria, S. Gulati, M. Powell, B. Annane, S. Cocke, J. Pinelli, K. Gurley, S. Chen, "Predicting Losses of Residential Structures in the State of Florida by the Public Hurricane Loss Evaluation Models", Statistical Methodology, vol. 7, issue 5, p. 552-573, September 2005.

G.J. Holland, "An Analytic Model of the Wind and Pressure Profiles in Hurricanes", Monthly Weather Review, vol.108, 1980.

Z. Huang, D.V. Rosowsky, P.R. Sparks, "Hurricane simulation techniques for the evaluation of wind-speeds and expected insurance losses", Journal of Wind Engineering and Industrial Aerodynamics, 89, 2001. 
HURDAT data, http://www.nhc.noaa.gov/data/hurdat/hurdat2-atlantic-1851-2012060513.txt

HURDAT easy to read data, http://www.aoml.noaa.gov/hrd/hurdat/easyread2012.html

M.K. James, L.B. Mason, "Synthetic Tropical Cyclone Database", Journal of Waterway, Port, Coastal, and Ocean Engineering, vol. 131, p. 181-192, 2005.

R. W. Katz, "Discussion on "Predicting losses of residential structures in the state of Florida by the public hurricane loss evaluation model" by S. Hamid et al.", Statistical Methodology, vol.7, p. 592-595, 2010.

P.J. Klotzbach, "Trends in global tropical cyclone activity over the past twenty years (1986-2005)", Geophysical Research Letters, vol. 33, 2006.

K.H. Lee, D.V. Rosowsky, "Synthetic Hurricane Wind Speed Records: Development of Database for Hazard Analyses and Risk Studies", National Hazards Review, vol. 8, p. 23-34, 2007.

R. Lokupitiya, L. Borgman, R. Anderson-Sprecher, "Simulation of Storm Occurrences Using Simulated Annealing", Journal of Climate, vol. 18, 2005.

M. Powell, G. Soukup, S. Cocke, S. Gulati, N. Morisseau-Leroy, S. Hamid, N. Dorst, L. Axe, "State of Florida hurricane projection model: Atmospheric science component", Journal of Wind Engineering and Industrial Aerodynamics, 93, p. 651$674,2005$.

L.R. Russell, "Probability distribution for Texas gulf coast hurricane effects of engineering interest", Ph.D. Thesis, Stanford University, 1968.

L.R. Russell, "Probability distributions for hurricane effects", Journal of Waterways, Harbors, and Coastal Engineering Division, 97, p.139-154, 1971.

A.H. El-Shaarawi, S.Chenouri, "Discussion on "Public Hurricane Loss Evaluation Models: Predicting losses of residential structures in the state of Florida" by S. Hamid et al..”, Statistical Methodology, 7 (5), p. 583-586, September 2010.

L.J. Shapiro, S.B. Goldenberg, "Atlantic sea surface temperatures and tropical cyclone formation", Journal of Climate, vol. 11, p. 578-590, 1998.

H.C.S. Thom, "Some Methods of Climatological Analysis", Technical Note, vol. 81, p. 30-34, 1966.

V.J. Tryggvason, A.G. Davenport, D. Surry, "Predicting Wind-Induced Response in Hurricane Zones", Journal of the Structural Division, 102, p.2333-2350, 1976. 
P.J. Vickery, F. Masters, M. Powell, D. Wadhera, "Hurricane hazard modeling: The past, present, and future", Journal of Wind Engineering and Industrial Aerodynamics, 2009.

P.J. Vickery, D. Wadhera, "Statistical Models of Holland Pressure Profile Parameter and Radius to Maximum Winds of Hurricanes from Flight-Level Pressure and H*Wind Data", Journal of Applied Meteorology and Climatology, vol. 47, p. 24972517, October 2008.

P.J. Webster, G.J. Holland, J.A. Curry, H.-R. Chang, "Changes in tropical cyclone number and intensity in a warming environment", Science, vol. 309, p. 1844-1846, 2005.

H.E. Willoughby, M.E. Rahn, "Parametric Representation of the Primary Hurricane Vortex. Part I: Observations and Evaluation of the Holland (1980) Model", American Meteorological Society, p. 3033-3048, December 2004. 


\section{APPENDICES}

\section{Appendix 1. Landfall $\boldsymbol{R}_{\max }$ database}

\begin{tabular}{|c|c|c|c|c|c|}
\hline Year & Name & Rmax (sm) & Po (mb) & LFLat & LFLon \\
\hline 1901 & No_name & 37.95 & 972.6 & 30.4 & 88.8 \\
\hline 1903 & No_name & 49.45 & 976.6 & 26.1 & 80.1 \\
\hline 1906 & No_name & 29.90 & 979 & 27.4 & 80.1 \\
\hline 1906 & No_name & 29.90 & 979 & 25.1 & 81 \\
\hline 1906 & No name & 34.50 & 976.6 & 33.3 & 79.2 \\
\hline 1906 & No name & 40.25 & 976.6 & 26.4 & 80.1 \\
\hline 1906 & No_name & 18.40 & 966.8 & 24.9 & 81 \\
\hline 1906 & No_name & 49.45 & 965.1 & 30.4 & 88.7 \\
\hline 1909 & No_name & 25.30 & 957 & 24.7 & 81 \\
\hline 1910 & No_name & 36.80 & 953.3 & 26 & 81.7 \\
\hline 1910 & No_name & 32.20 & 941.4 & 24.4 & 82.7 \\
\hline 1911 & No_name & 31.05 & 979.3 & 32.2 & 80.6 \\
\hline 1915 & No_name & 29.90 & 932.3 & 29.2 & 90 \\
\hline 1916 & No_name & 21.85 & 973.9 & 30.3 & 87.5 \\
\hline 1916 & No_name & 29.90 & 950.2 & 30.4 & 88.3 \\
\hline 1917 & No_name & 37.95 & 964.4 & 30.4 & 86.7 \\
\hline 1919 & No_name & 17.25 & 929.2 & 24.6 & 82.9 \\
\hline 1921 & No_name & 20.70 & 960 & 27.9 & 82.8 \\
\hline 1924 & No_name & 24.15 & 978.3 & 25.5 & 81.7 \\
\hline 1924 & No_name & 21.85 & 971.9 & 24.6 & 82.9 \\
\hline 1926 & No_name & 16.10 & 959.7 & 29.9 & 81.3 \\
\hline 1926 & No_name & 19.55 & 955 & 30.3 & 87.5 \\
\hline 1926 & No_name & 27.60 & 950 & 26.4 & 81.9 \\
\hline 1926 & No_name & 24.15 & 931.9 & 23.9 & 80.4 \\
\hline 1926 & No_name & 21.85 & 931 & 25.6 & 80.3 \\
\hline 1928 & No_name & 32.20 & 935.3 & 26.7 & 80 \\
\hline 1929 & No_name & 32.20 & 948.2 & 25 & 80.5 \\
\hline 1933 & No_name & 14.95 & 947.5 & 26.9 & 80.1 \\
\hline 1935 & No_name & 11.50 & 977 & 25.2 & 81.1 \\
\hline 1935 & No_name & 11.50 & 972.9 & 25.9 & 80.1 \\
\hline 1936 & No_name & 21.85 & 963.8 & 30.4 & 86.4 \\
\hline 1940 & No_name & 31.05 & 974.6 & 32.1 & 80.8 \\
\hline 1941 & No_name & 20.70 & 981.4 & 29.8 & 84.7 \\
\hline 1944 & No_name & 33.35 & 948.9 & 24.6 & 82.8 \\
\hline 1945 & No_name & 13.80 & 951.2 & 25.3 & 80.3 \\
\hline 1947 & No_name & 14.95 & 968.2 & 31.9 & 81.1 \\
\hline 1947 & No_name & 26.45 & 966.5 & 29.6 & 89.5 \\
\hline 1947 & No_name & 29.90 & 960 & 26.3 & 81.8 \\
\hline 1947 & No_name & 29.90 & 946.8 & 26.3 & 80.1 \\
\hline 1948 & No_name & 18.40 & 977 & 25.9 & 80.1 \\
\hline 1948 & No_name & 18.40 & 963.4 & 27.2 & 80.2 \\
\hline 1948 & No_name & 14.95 & 962.7 & 24.8 & 81 \\
\hline 1948 & No_name & 18.40 & 950.9 & 25.9 & 81.7 \\
\hline
\end{tabular}




\begin{tabular}{|c|c|c|c|c|c|}
\hline Year & Name & Rmax (sm) & Po (mb) & LFLat & LFLon \\
\hline 1948 & No_name & 8.05 & 935.3 & 24.6 & 81.7 \\
\hline 1949 & No_name & 26.45 & 953.6 & 26.9 & 80 \\
\hline 1950 & Baker & 24.15 & 979.3 & 30.2 & 88.1 \\
\hline 1950 & Easy & 17.25 & 958.3 & 28.6 & 82.7 \\
\hline 1950 & King & 6.90 & 955 & 26.1 & 80.1 \\
\hline 1956 & Flossy & 20.70 & 973.9 & 30.4 & 86.4 \\
\hline 1958 & Helene & 28.75 & 932 & 32.7 & 78.7 \\
\hline 1959 & Gracie & 29.90 & 950.9 & 32.5 & 80.4 \\
\hline 1960 & Ethel & 25.30 & 976 & 30.3 & 89.3 \\
\hline 1960 & Donna & 27.60 & 970 & 29.5 & 81.1 \\
\hline 1960 & Donna & 20.70 & 930 & 24.8 & 80.9 \\
\hline 1964 & Isbell & 14.95 & 977.7 & 26.9 & 80 \\
\hline 1964 & Cleo & 8.05 & 967.5 & 25.7 & 80.2 \\
\hline 1964 & Isbell & 11.50 & 964.1 & 25.8 & 81.3 \\
\hline 1964 & Dora & 39.10 & 961 & 29.9 & 81.3 \\
\hline 1965 & Betsy & 25.30 & 951.9 & 25 & 80.5 \\
\hline 1966 & Alma & 23.00 & 977 & 30.1 & 84.2 \\
\hline 1966 & Inez & 17.25 & 977 & 24.1 & 84.1 \\
\hline 1966 & Alma & 17.25 & 970.2 & 24.6 & 82.9 \\
\hline 1968 & Gladys & 19.55 & 977 & 28.6 & 82.7 \\
\hline 1972 & Agnes & 23.00 & 978 & 29.9 & 85.4 \\
\hline 1975 & Eloise & 16.10 & 955 & 30.3 & 86.5 \\
\hline 1976 & Belle & 28.75 & 963.1 & 32.5 & 75.2 \\
\hline 1979 & David & 11.50 & 968 & 31.6 & 81.2 \\
\hline 1979 & David & 31.05 & 968 & 27.1 & 80.1 \\
\hline 1979 & Frederic & 37.95 & 946 & 30.4 & 88.3 \\
\hline 1985 & Bob & 27.95 & 1003 & 32.2 & 80.5 \\
\hline 1985 & Elena & 46.58 & 971 & 28.8 & 83.8 \\
\hline 1985 & Kate & 27.95 & 967 & 30 & 85.4 \\
\hline 1985 & Elena & 17.20 & 959 & 30.4 & 89.2 \\
\hline 1985 & Elena & 18.63 & 954 & 29.4 & 85.9 \\
\hline 1987 & Floyd & 15.53 & 993 & 24.8 & 81 \\
\hline 1988 & FLORENCE & 28.75 & 983 & 28.7 & 89.3 \\
\hline 1989 & HUGO & 40.25 & 935 & 31.7 & 78.8 \\
\hline 1991 & BOB & 34.50 & 965 & 33 & 76.1 \\
\hline 1992 & ANDREW & 17.25 & 947 & 25.8 & 83.1 \\
\hline 1995 & ERIN & 46.00 & 988 & 29.6 & 83.4 \\
\hline 1995 & ERIN & 23.00 & 985 & 30.6 & 87.5 \\
\hline 1995 & ERIN & 46.00 & 985 & 27.7 & 80.4 \\
\hline 1995 & ERIN & 23.00 & 974 & 29.8 & 86.6 \\
\hline 1995 & OPAL & 28.75 & 938 & 29 & 87.7 \\
\hline 1996 & BERTHA & 28.75 & 984 & 31.2 & 78.6 \\
\hline 1996 & FRAN & 23.00 & 954 & 31 & 77.2 \\
\hline 1997 & DANNY & 34.50 & 992 & 29.2 & 89.9 \\
\hline 1997 & DANNY & 11.50 & 990 & 29.5 & 89.4 \\
\hline 1997 & DANNY & 17.25 & 984 & 30.3 & 88 \\
\hline 1998 & GEORGES & 34.50 & 982 & 23.9 & 81.3 \\
\hline
\end{tabular}




\begin{tabular}{|l|lrrrr|}
\hline \multicolumn{1}{|c|}{ Near } & Namax $(\mathrm{sm})$ & Po $(\mathrm{mb})$ & \multicolumn{1}{c|}{ LFLat } & \multicolumn{1}{c|}{ LFLon } \\
\hline 1998 GEORGES & 34.50 & 965 & 30.4 & 88.9 \\
1998 BONNIE & 46.00 & 958 & 30.8 & 76.4 \\
1999 IRENE & 46.00 & 982 & 27.8 & 80.1 \\
1999 DENNIS & 46.00 & 967 & 30.8 & 78.4 \\
1999 FLOYD & 40.25 & 947 & 30.6 & 79.1 \\
2004 FRANCES & 37.95 & 960 & 27.2 & 80.2 \\
2004 JEANNE & 51.75 & 953 & 27.3 & 80.2 \\
2004 CHARLEY & 5.75 & 947 & 26.56 & 82.29 \\
2004 IVAN & 26.45 & 943 & 30.2 & 87.8 \\
2005 KATRINA & 10.72 & 986 & 25.88 & 80.13 \\
2005 RITA & 12.65 & 976 & 23.75 & 82 \\
2005 WILMA & 52.90 & 951 & 25.92 & 81.58 \\
2005 DENNIS & 5.75 & 946 & 30.38 & 87.05 \\
2005 DENNIS Cubi & 9.19 & 937 & 22.1 & 80.6 \\
2005 KATRINA & 19.55 & 932 & 30.25 & 89.62 \\
2007 Humberto & 12.65 & 985 & 29.5 & 94.4 \\
2008 Dolly & 6.90 & 967 & 26.4 & 97.2 \\
2008 Paloma_Cubi & 14.95 & 970 & 20.7 & 78 \\
2008 Gustav & 29.90 & 941 & 22.4 & 83.1 \\
2008 Ike & 42.55 & 950 & 29.3 & 94.7 \\
2010 Paula_Cuba & 16.10 & 1000 & 22.7 & 83.9 \\
2010 Earl & 31.00 & 935 & 30.1 & 74.8 \\
\hline
\end{tabular}


Appendix 2. Holland B database

\begin{tabular}{|c|c|c|c|c|c|c|c|}
\hline Hurricane Name & Pmin & B & $\operatorname{Rmax}$ & DelP^2 & Vmax & Lat & Lon \\
\hline 1 LILI96_18H1 & 978 & 0.69 & 78 & 1225 & 30.02 & 21.83 & -82.13 \\
\hline 2 ERIN95_01U1 & 990 & 1.24 & 42.5 & 529 & 30.47 & 25.42 & -76.32 \\
\hline 3 GEORGES98_25I1 & 981 & 1.5 & 72.5 & 1024 & 30.59 & 23.43 & -80.15 \\
\hline 4 ROXANNE95_16U1 & 982 & 1.18 & 38 & 961 & 30.86 & 20.35 & -92.11 \\
\hline 5 FLORENCE88_09H & 991 & 1.36 & 36 & 484 & 30.98 & 28.67 & -89.34 \\
\hline 6 DAVID79_02H & 993 & 1.24 & 46.5 & 400 & 31.29 & 24.41 & -78.03 \\
\hline 7 ALICIA83_17I & 982 & 1.21 & 36 & 961 & 31.3 & 27.68 & -93.83 \\
\hline 8 BONNIE98_22U1 & 990 & 1.16 & 30.5 & 529 & 31.32 & 22.69 & -70.14 \\
\hline 9 BOB91_18Ū1 & 979 & 0.78 & 44 & 1156 & 31.38 & 30.7 & -76.82 \\
\hline 10 DAVID79_02I & 988 & 1.47 & 48.5 & 625 & 31.56 & 23.67 & -77.04 \\
\hline 11 DANNY85_15I1 & 993 & 1.69 & 58.5 & 400 & 31.73 & 29.61 & -92.7 \\
\hline 12 DANNY85_15H1 & 993 & 2.06 & 62 & 400 & 32.1 & 28.59 & -92.33 \\
\hline 13 DANIELLE988_30I & 988 & 1.32 & 37.5 & 625 & 32.16 & 27.84 & -74.16 \\
\hline 14 FRAN96_03U1 & 976 & 1.28 & 76.5 & 1369 & 32.17 & 24.68 & -70.65 \\
\hline 15 DANIELLE998_31U3 & 976 & 1.01 & 32.5 & 1369 & 32.35 & 31.14 & -73.23 \\
\hline 16 DANIELLE98_30U2 & 988 & 1.2 & 32.5 & 625 & 32.46 & 28.13 & -74.27 \\
\hline 17 ERIN95_01U2 & 986 & 1.45 & 37.5 & 729 & 32.89 & 26.47 & -78.09 \\
\hline 18 GEORGES98_28U2 & 966 & 0.93 & 32.5 & 2209 & 33.29 & 30.45 & -88.9 \\
\hline 19 OPAL95_03U 2 & 967 & 1.09 & 27 & 2116 & 33.75 & 24.13 & -90.34 \\
\hline 20 DAVID79_03F & 974 & 1.33 & 38 & 1521 & 33.81 & 25.57 & -79.25 \\
\hline 21 ELENA85_1_30I & 980 & 0.85 & 70 & 1089 & 33.9 & 27.47 & -87.44 \\
\hline 22 BERTHA96_09U2 & 963 & 0.87 & 78 & 2500 & 33.95 & 23.63 & -72.5 \\
\hline 23 DENNIS99_28U1 & 969 & 1.18 & 60.5 & 1936 & 34.01 & 27.01 & -76.93 \\
\hline 24 OPAL95_03̄U1A & 969 & 1.53 & 42.5 & 1936 & 34.23 & 22.26 & -92.2 \\
\hline 25 ERIN95_02U2 & 987 & 1.51 & 33.5 & 676 & 34.44 & 29.15 & -85.52 \\
\hline 26 GEORGES98_25H1 & 981 & 1.31 & 66.5 & 1024 & 35.11 & 24.27 & -81.81 \\
\hline 27 GEORGES98_25U1 & 986 & 1.18 & 46.5 & 729 & 35.15 & 24.83 & -83.15 \\
\hline 28 DANIELLE98_31U1 & 982 & 1.27 & 28 & 961 & 35.19 & 29.68 & -73.81 \\
\hline 29 DANIELLE98_01U1 & 973 & 0.83 & 77.5 & 1600 & 35.55 & 32.38 & -71.6 \\
\hline 30 GEORGES98_26U1 & 974 & 1.24 & 46 & 1521 & 35.74 & 25.43 & -84.41 \\
\hline 31 GEORGES98_27U2 & 966 & 0.84 & 61 & 2209 & 35.92 & 29.03 & -88.32 \\
\hline 32 GEORGES98_26U3 & 975 & 1.09 & 38.5 & 1444 & 36.29 & 27.2 & -86.79 \\
\hline 33 GEORGES98_26U2 & 974 & 1.06 & 38 & 1521 & 36.5 & 26.32 & -85.75 \\
\hline 34 BERTHA96_12U2 & 979 & 1.15 & 74.5 & 1156 & 36.71 & 32.75 & -78.1 \\
\hline 35 BERTHA96_09U1 & 965 & 1.14 & 34 & 2304 & 37.24 & 21.95 & -70.09 \\
\hline 36 GEORGES98_28U1 & 962 & 1.2 & 40.5 & 2601 & 37.46 & 29.8 & -88.73 \\
\hline 37 ELENA85_2_31H & 975 & 1.31 & 68 & 1444 & 37.55 & 28.77 & -84.27 \\
\hline 38 EMILY93_29U4 & 978 & 1.45 & 47.5 & 1225 & 37.59 & 31.43 & -70.37 \\
\hline 39 GEORGES98_27U1 & 970 & 1.02 & 42.5 & 1849 & 37.71 & 28.21 & -87.73 \\
\hline 40 ELENA85_2_31I & 975 & 1.04 & 68 & 1444 & 37.72 & 28.78 & -83.82 \\
\hline 41 ERIN95_03U1 & 982 & 1.57 & 24.5 & 961 & 37.91 & 30.02 & -86.77 \\
\hline 42 BOB91_18U2 & 976 & 1.17 & 29.5 & 1369 & 38.01 & 32.99 & -76.07 \\
\hline 43 ELENA85_2_3012 & 976 & 1.39 & 66.5 & 1369 & 38.24 & 28.52 & -85.36 \\
\hline 44 GLORIA85_3_26I & 945 & 1 & 45.5 & 4624 & 38.69 & 29.26 & -75.13 \\
\hline 45 DENNIS99_29u2 & 971 & 1.44 & 58 & 1764 & 39.21 & 32.09 & -78.04 \\
\hline
\end{tabular}




\begin{tabular}{|c|c|c|c|c|c|c|c|c|}
\hline & Hurricane Name & Pmin & B & $\operatorname{Rmax}$ & DelP^2 & Vmax & Lat & Lon \\
\hline & FLOYD99_15U3 & 945 & 1.66 & 54.5 & 4624 & 39.25 & 33.59 & -77.96 \\
\hline & DENNIS99_28U3 & 979 & 1.62 & 75 & 1156 & 39.4 & 28.96 & -77.93 \\
\hline 48 & GILBERT88 15 II & 947 & 1.02 & 68.5 & 4356 & 39.53 & 21.97 & -92.07 \\
\hline 49 & ALICIA83_17̄H & 982 & 1.43 & 32.5 & 961 & 39.7 & 27.97 & -94.37 \\
\hline 50 & BONNIE98_25U2 & 963 & 1.21 & 86.5 & 2500 & 39.72 & 31.31 & -76.9 \\
\hline 51 & ALICIA83_17I2 & 979 & 1.16 & 20.5 & 1156 & 40.13 & 28.49 & -94.69 \\
\hline 52 & BONNIE98_26U1 & 961 & 1.32 & 84 & 2704 & 40.25 & 32.54 & -77.67 \\
\hline 53 & LILI96_18H'̄ & 975 & 1.52 & 42 & 1444 & 40.73 & 23.24 & -77.14 \\
\hline 54 & DENNIS99_29U1 & 970 & 1.73 & 70 & 1849 & 40.81 & 30.34 & -78.27 \\
\hline 55 & GILBERT88_1512 & 950 & 1.22 & 54.5 & 3969 & 40.86 & 22.7 & -94.18 \\
\hline 56 & HORTENSE96_13U1 & 938 & 0.98 & 17 & 5625 & 41 & 27.96 & -71.19 \\
\hline 57 & DENNIS99_28U2 & 974 & 1.27 & 90.5 & 1521 & 41.08 & 27.95 & -77.5 \\
\hline 58 & BONNIE98_22U2 & 984 & 1.25 & 40 & 841 & 41.27 & 23.62 & -71.26 \\
\hline 59 & BONNIE98_24U2 & 961 & 1.17 & 83.5 & 2704 & 41.38 & 27.16 & -73.24 \\
\hline 60 & DIANA84_2__12I & 960 & 1.26 & 16 & 2809 & 41.55 & 33.96 & -77.17 \\
\hline 61 & FRAN96_05U1 & 949 & 0.97 & 83 & 4096 & 41.64 & 30.82 & -77.13 \\
\hline 62 & DIANA84_2_11I & 958 & 1.57 & 24 & 3025 & 41.74 & 31.69 & -78.73 \\
\hline 63 & FRAN96_05U2 & 953 & 0.99 & 92.5 & 3600 & 41.77 & 33 & -77.86 \\
\hline 64 & EMILY93_30U2 & 975 & 1.52 & 35 & 1444 & 42.04 & 32.35 & -73.07 \\
\hline 65 & FRAN96_04U3 & 954 & 0.8 & 90.5 & 3481 & 42.15 & 29.09 & -76.31 \\
\hline 66 & BONNIE98_26U2 & 964 & 1.31 & 78.5 & 2401 & 42.29 & 33.8 & -77.86 \\
\hline 67 & DIANA84_2_12H2 & 968 & 1.49 & 29.5 & 2025 & 42.33 & 33.86 & -77.6 \\
\hline 68 & FREDERIC79_11H & 976 & 1.76 & 37.5 & 1369 & 42.67 & 24.69 & -85.15 \\
\hline 69 & EDOUARD96_31U1 & 947 & 1.09 & 56 & 4356 & 42.86 & 32.11 & -70.15 \\
\hline 70 & ELENA85_2_01H & 962 & 1.39 & 36 & 2601 & 42.98 & 28.58 & -84.07 \\
\hline 71 & FLOYD99_15U2 & 939 & 1.42 & 63 & 5476 & 43.16 & 31.14 & -78.88 \\
\hline 72 & BONNIE98_23U3 & 957 & 0.97 & 92.5 & 3136 & 43.35 & 24.99 & -71.9 \\
\hline 73 & EMILY93_31U1 & 971 & 1.63 & 39.5 & 1764 & 43.41 & 33.05 & -74.23 \\
\hline 74 & FRAN96_03U2 & 974 & 1.75 & 56 & 1521 & 43.77 & 25.48 & -72.64 \\
\hline 75 & FREDERIC79_11IA & 976 & 1.69 & 37.5 & 1369 & 43.8 & 25.44 & -85.5 \\
\hline 76 & FLOYD99_15I & 939 & 1.68 & 49 & 5476 & 43.86 & 32.16 & -78.55 \\
\hline 77 & BONNIE98_23U1 & 961 & 1.39 & 33.5 & 2704 & 44.14 & 24.2 & -71.56 \\
\hline 78 & FRAN96_04U1 & 957 & 1.46 & 45 & 3136 & 45.03 & 27.7 & -75.4 \\
\hline 79 & BONNIE98_26I & 961 & 1.33 & 79.5 & 2704 & 45.03 & 33.69 & -77.87 \\
\hline 80 & BONNIE98_24U1 & 957 & 1.33 & 91.5 & 3136 & 45.19 & 25.73 & -72.44 \\
\hline 81 & HORTENSE96_11I1 & 976 & 1.73 & 27 & 1369 & 45.58 & 21.86 & -70.84 \\
\hline 82 & BONNIE98_24I- & 960 & 1.4 & 76 & 2809 & 46.04 & 26.68 & -72.97 \\
\hline 83 & FRAN96_05 & 952 & 1.43 & 72 & 3721 & 46.48 & 33.44 & -77.97 \\
\hline 84 & OPAL95_04U1 & 944 & 0.96 & 17.5 & 4761 & 46.76 & 26.45 & -88.95 \\
\hline 85 & FREDERIC79_11IC & 976 & 1.65 & 32.5 & 1369 & 48.33 & 26.06 & -86.15 \\
\hline 86 & ELENA85_2_0̄1I & 962 & 1.46 & 28.5 & 2601 & 48.72 & 28.89 & -84.63 \\
\hline 87 & FREDERIC79_12F & 951 & 0.95 & 68 & 3844 & 48.77 & 28.14 & -87.42 \\
\hline 88 & EDOUARD96_30U2 & 938 & 0.88 & 65 & 5625 & 48.83 & 29.62 & -70.45 \\
\hline 89 & ANDREW92_-25U2 & 947 & 1.22 & 31 & 4356 & 49.28 & 27.07 & -87.96 \\
\hline 90 & HORTENSE96_12H1 & 956 & 1.62 & 23 & 3249 & 49.75 & 23.28 & -71.58 \\
\hline 91 & FLOYD99_15U1 & 934 & 1.71 & 65 & 6241 & 49.91 & 29.25 & -78.88 \\
\hline 92 & FLOYD99_14U1 & 926 & 1.25 & 35.5 & 7569 & 49.96 & 25.05 & -75.66 \\
\hline
\end{tabular}




\begin{tabular}{|lrr|r|r|r|r|r|}
\hline \multicolumn{1}{|c|}{ Hurricane Name } & Pmin & \multicolumn{1}{c|}{ B } & Rmax & DelP^2 & Vmax & Lat & \multicolumn{1}{c|}{ Lon } \\
\hline 93 FREDERIC79_11IB & 976 & 2.06 & 37.5 & 1369 & 50.58 & 25.81 & -85.7 \\
94 ELENA85_2_02I & 956 & 1.6 & 30 & 3249 & 50.66 & 29.66 & -87.15 \\
95 ANDREW92_22U2 & 988 & 1.69 & 16 & 625 & 51.04 & 25.67 & -71.68 \\
96 DIANA84_2_11H & 966 & 1.59 & 16.5 & 2209 & 51.28 & 32.83 & -78.23 \\
97 FREDERIC79_12H2 & 951 & 1.64 & 46 & 3844 & 51.38 & 29.97 & -88.2 \\
98 ANDREW92_24U1 & 933 & 1.32 & 17 & 6400 & 51.39 & 25.85 & -83.54 \\
99 FREDERIC79_12H1B & 951 & 1.58 & 32 & 3844 & 51.96 & 27.05 & -86.8 \\
100 DIANA84_2_1112 & 956 & 1.49 & 17.5 & 3249 & 52.81 & 33.72 & -77.71 \\
101 ANDREW92_25U4 & 943 & 1.59 & 27 & 4900 & 53.13 & 29.15 & -91.3 \\
102 FLOYD99_14U2 & 928 & 1.22 & 69.5 & 7225 & 53.23 & 26.05 & -76.86 \\
103 ALLEN80_06I & 955 & 1.64 & 24 & 3364 & 53.4 & 20.15 & -81.42 \\
104 EDOUARD96_30U1 & 940 & 1.5 & 29.5 & 5329 & 54.12 & 27.83 & -70.28 \\
105 HORTENSE96_12U1 & 964 & 1.66 & 16.5 & 2401 & 54.92 & 25.09 & -71.66 \\
106 FLOYD99_13I & 923.5 & 1.57 & 35 & 8010.25 & 55.6 & 24.41 & -73.73 \\
107 FLOYD99_14U3 & 930 & 1.71 & 66 & 6889 & 56.79 & 27.62 & -77.87 \\
108 ANDREW92_23U2 & 940 & 1.29 & 12 & 5329 & 56.88 & 25.43 & -77.05 \\
109 ALLEN80_08I & 940 & 1.56 & 15 & 5329 & 57.58 & 24.28 & -92.47 \\
110 FREDERIC79_12H1A & 951 & 2 & 30.5 & 3844 & 58.35 & 26.54 & -86.51 \\
111 ANDREW92_25U3 & 948 & 1.66 & 27.5 & 4225 & 59.64 & 28.09 & -90.09 \\
112 FLOYD99_13U1 & 927 & 1.68 & 35 & 7396 & 60.66 & 23.78 & -70.6 \\
113 ANDREW92_23U3 & 927 & 1.68 & 20 & 7396 & 62.26 & 25.46 & -79.54 \\
114 ANDREW92_23U1 & 954 & 1.58 & 13.5 & 3481 & 63.42 & 25.38 & -75.04 \\
115 GILBERT88_14H1 & 889 & 1.38 & 12 & 15376 & 63.61 & 20.16 & -85.75 \\
116 ALLEN80_07H & 905 & 1.95 & 16.5 & 11664 & 76.28 & 21.77 & -86.46 \\
\hline
\end{tabular}




\section{Appendix 3. SAS codes}

A. SAS code for estimation Holland $B$ using the radius of maximum winds and latitude

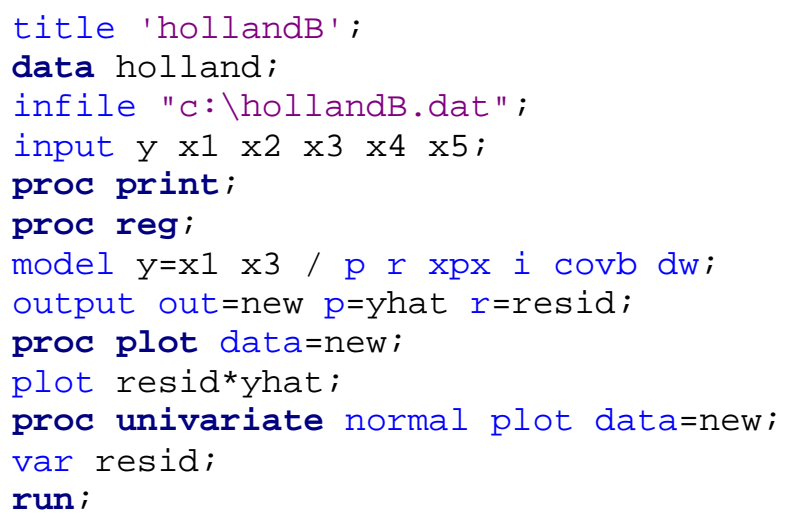

B. SAS code for estimation Holland $B$ using the radius of maximum winds, the square difference between central minimum sea level pressure and an outer peripheral pressure and latitude

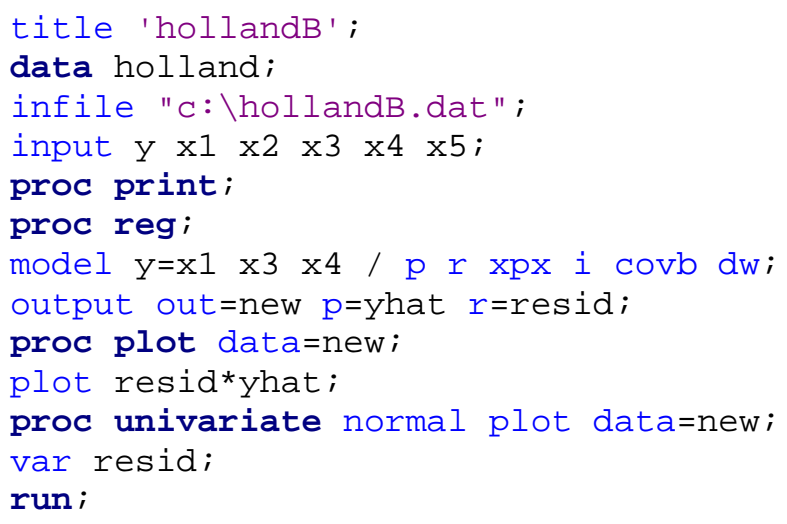

C. SAS code for estimation Holland $B$ using the latitude, the longitude, the radius of maximum winds, the square difference between central minimum sea level pressure and an outer peripheral pressure and the maximum wind

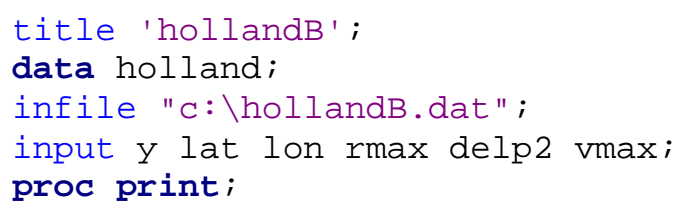




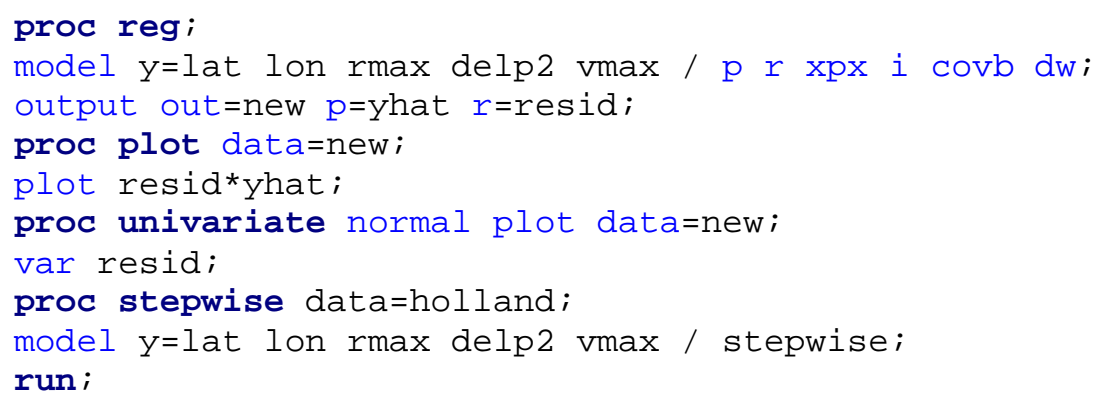

D. SAS code for estimation Holland B using the radius of maximum winds, the square difference between central minimum sea level pressure and an outer peripheral pressure and the maximum wind

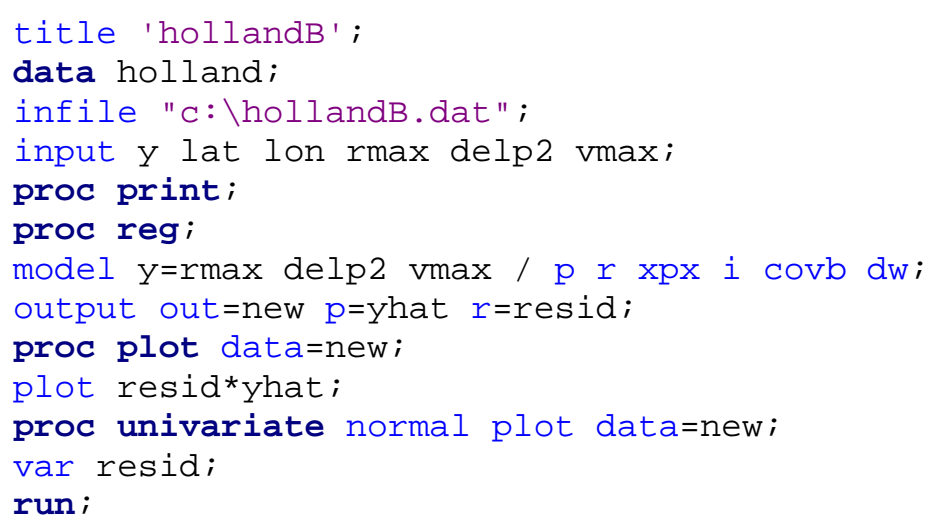




\section{Appendix 4. SAS output}

A. SAS output using the radius of maximum winds and latitude

\begin{tabular}{|l|r|r|r|r|r|}
\hline \multicolumn{5}{|c|}{ Analysis of Variance } \\
\hline Source & DF & $\begin{array}{r}\text { Sum of } \\
\text { Squares }\end{array}$ & $\begin{array}{r}\text { Mean } \\
\text { Square }\end{array}$ & F Value & Pr > F \\
\hline Model & 2 & 1.07527 & 0.53763 & 7.14 & 0.0012 \\
\hline Error & 113 & 8.51376 & 0.07534 & & \\
\hline Corrected Total & 115 & 9.58903 & & & \\
\hline
\end{tabular}

\begin{tabular}{|l|r|l|l|}
\hline Root MSE & 0.27449 & R-Square & 0.1121 \\
\hline Dependent Mean & 1.35422 & Adj R-Sq & 0.0964 \\
\hline Coeff Var & 20.26894 & & \\
\hline
\end{tabular}

\begin{tabular}{|l|r|r|r|r|r|}
\hline \multicolumn{7}{|c|}{ Parameter Estimates } \\
\hline Variable & DF & $\begin{array}{r}\text { Parameter } \\
\text { Estimate }\end{array}$ & $\begin{array}{r}\text { Standard } \\
\text { Error }\end{array}$ & $\mathbf{t}$ Value & Pr $>|\mathbf{t}|$ \\
\hline Intercept & 1 & 1.55384 & 0.20482 & 7.59 & $<.0001$ \\
\hline $\mathbf{x 1}$ & 1 & 0.00015058 & 0.00750 & 0.02 & 0.9840 \\
\hline $\mathbf{x} 2$ & 1 & -0.00439 & 0.00119 & -3.70 & 0.0003 \\
\hline
\end{tabular}


B. SAS output using the radius of maximum winds, the square difference between central minimum sea level pressure and an outer peripheral pressure and latitude

\begin{tabular}{|l|r|r|r|r|r|}
\hline \multicolumn{5}{|c|}{ Analysis of Variance } \\
\hline Source & DF & $\begin{array}{r}\text { Sum of } \\
\text { Squares }\end{array}$ & $\begin{array}{r}\text { Mean } \\
\text { Square }\end{array}$ & F Value & Pr > F \\
\hline Model & 3 & 1.12264 & 0.37421 & 4.95 & 0.0029 \\
\hline Error & 112 & 8.46639 & 0.07559 & & \\
\hline Corrected Total & 115 & 9.58903 & & & \\
\hline
\end{tabular}

\begin{tabular}{|l|r|l|l|}
\hline Root MSE & 0.27494 & R-Square & 0.1171 \\
\hline Dependent Mean & 1.35422 & Adj R-Sq & 0.0934 \\
\hline Coeff Var & 20.30250 & & \\
\hline
\end{tabular}

\begin{tabular}{|l|r|r|r|r|r|}
\hline \multicolumn{7}{|c|}{ Parameter Estimates } \\
\hline Variable & DF & $\begin{array}{r}\text { Parameter } \\
\text { Estimate }\end{array}$ & $\begin{array}{r}\text { Standard } \\
\text { Error }\end{array}$ & t Value & $\operatorname{Pr}>|t|$ \\
\hline Intercept & 1 & 1.50264 & 0.21511 & 6.99 & $<.0001$ \\
\hline x1 & 1 & 0.00086116 & 0.00757 & 0.11 & 0.9096 \\
\hline x2 & 1 & -0.00426 & 0.00120 & -3.55 & 0.0006 \\
\hline x3 & 1 & 0.00000885 & 0.00001118 & 0.79 & 0.4302 \\
\hline
\end{tabular}


C. SAS output using the latitude, the longitude, the radius of maximum winds, the square difference between central minimum sea level pressure and an outer peripheral pressure and the maximum wind

\begin{tabular}{|l|r|r|r|r|r|}
\hline \multicolumn{5}{|c|}{ Analysis of Variance } \\
\hline Source & DF & $\begin{array}{r}\text { Sum of } \\
\text { Squares }\end{array}$ & $\begin{array}{r}\text { Mean } \\
\text { Square }\end{array}$ & F Value & Pr > F \\
\hline Model & 5 & 3.59077 & 0.71815 & 13.17 & $<.0001$ \\
\hline Error & 110 & 5.99826 & 0.05453 & & \\
\hline Corrected Total & 115 & 9.58903 & & & \\
\hline
\end{tabular}

\begin{tabular}{|l|r|l|l|}
\hline Root MSE & 0.23352 & R-Square & 0.3745 \\
\hline Dependent Mean & 1.35422 & Adj R-Sq & 0.3460 \\
\hline Coeff Var & 17.24352 & & \\
\hline
\end{tabular}

\begin{tabular}{|l|r|r|r|r|r|}
\hline \multicolumn{7}{|c|}{ Parameter Estimates } \\
\hline Variable & DF & $\begin{array}{r}\text { Parameter } \\
\text { Estimate }\end{array}$ & $\begin{array}{r}\text { Standard } \\
\text { Error }\end{array}$ & $t$ Value & $\mathrm{Pr}>|\mathrm{t}|$ \\
\hline Intercept & 1 & 0.25712 & 0.37454 & 0.69 & 0.4938 \\
\hline lat & 1 & -0.00100 & 0.00646 & -0.16 & 0.8770 \\
\hline lon & 1 & -0.00308 & 0.00319 & -0.97 & 0.3365 \\
\hline rmax & 1 & -0.00157 & 0.00110 & -1.42 & 0.1588 \\
\hline delp2 & 1 & -0.00006305 & 0.00001434 & -4.40 & $<.0001$ \\
\hline vmax & 1 & 0.02652 & 0.00395 & 6.72 & $<.0001$ \\
\hline
\end{tabular}


D. SAS output using the radius of maximum winds, the square difference between central minimum sea level pressure and an outer peripheral pressure and the maximum wind

\begin{tabular}{|l|r|r|r|r|r|}
\hline \multicolumn{5}{|c|}{ Analysis of Variance } \\
\hline Source & DF & $\begin{array}{r}\text { Sum of } \\
\text { Squares }\end{array}$ & $\begin{array}{r}\text { Mean } \\
\text { Square }\end{array}$ & F Value & Pr $>$ F \\
\hline Model & 3 & 3.53710 & 1.17903 & 21.82 & $<.0001$ \\
\hline Error & 112 & 6.05193 & 0.05404 & & \\
\hline Corrected Total & 115 & 9.58903 & & & \\
\hline
\end{tabular}

\begin{tabular}{|l|r|l|l|}
\hline Root MSE & 0.23245 & R-Square & 0.3689 \\
\hline Dependent Mean & 1.35422 & Adj R-Sq & 0.3520 \\
\hline Coeff Var & 17.16514 & & \\
\hline
\end{tabular}

\begin{tabular}{|l|r|r|r|r|r|}
\hline \multicolumn{7}{|c|}{ Parameter Estimates } \\
\hline Variable & DF & $\begin{array}{r}\text { Parameter } \\
\text { Estimate }\end{array}$ & $\begin{array}{r}\text { Standard } \\
\text { Error }\end{array}$ & $\mathrm{t}$ Value & $\operatorname{Pr}>|\mathrm{t}|$ \\
\hline Intercept & 1 & 0.50274 & 0.16479 & 3.05 & 0.0028 \\
\hline rmax & 1 & -0.00181 & 0.00106 & -1.70 & 0.0915 \\
\hline delp2 & 1 & -0.00006228 & 0.00001417 & -4.39 & $<.0001$ \\
\hline vmax & 1 & 0.02612 & 0.00391 & 6.69 & $<.0001$ \\
\hline
\end{tabular}

